\title{
Scalar implicatures under uncertainty
}

\author{
by
}

Cathy Agyemang

A thesis submitted to the Institute of Cognitive Science in partial fulfillment of the requirements for the degree of

\section{Master of Cognitive Science}

in Cognitive Science

\author{
Carleton University \\ Ottawa, Ontario
}

(C) 2020

Cathy Agyemang 


\section{Abstract}

Studies on judgments under uncertainty argue that individuals reason about the likelihoods of events in ways that are inconsistent with the basic axioms of probability. However, such studies fail to consider that the information expressed can be ambiguous between literal and strengthened meanings, through scalar implicatures. Under a literal interpretation, intuitive judgments may appear to violate the rules of probability. However, scalar implicatures change meanings, such that, probability theory alone does not determine how people make judgments. Instead, individuals rely on experience, prior knowledge and other cognitive factors. I examine the availability of scalar implicatures under uncertainty and its influence on perceived event likelihood. Comparing contexts where an implicature is available to where it is not, I present evidence that violations of probability theory occur only in conditions where scalar implicatures are available. Thus, probabilistic judgments must also consider how individuals apply conversational reasoning in order to resolve uncertainty. 


\section{Acknowledgments}

Completing my Master's was an incredibly humbling experience. This work would not have been at all possible without the efforts of many people. To avoid waxing poetic, I will briefly acknowledge the contributions of some of these individuals here. First, I would like to thank my thesis committee, Deepthi Kamawar, Ida Toivonen and Ai Taniguchi for their careful consideration of this thesis. I want to express my gratitude for their intelligent questions and insightful feedback that challenged my understanding of the work and greatly improved it. I would like to thank the reviewers and audiences at TOM 2019, WeSSLLI 2020 and ELM 2020 for their keen interest and comments on various iterations of this work.

Above all, I would like to sincerely thank my supervisor, Raj Singh. My thinking, and deep appreciation for the study of scalar implicatures are largely due to his patience, expertise and mentorship and I am immensely grateful for it. Thank you for the fruitful conversations and kindness that always helped me as I (often clumsily) worked through my ideas.

I would like to thank my friends, back in Edmonton, in Ottawa, and all around the world. To those who didn't hesitate to pilot study after study. To those outside of academia, who constantly remind me how much more there is to life than graduate school. To my colleagues at the National Research Council Canada: Chunyun Ma, who shares my enthusiasm about statistics and Max Kinateder, who has an infectious optimism and curiosity about research. To my friends and colleagues in the Cognitive Science department, especially from the Cognitive Science Graduate Student Association. Their genuine warmth, kindness and friendship made my graduate school experience so much richer. My deepest thanks to friends who took the time and care to ask how I was doing, often at times when I needed it the most. I owe a special thanks to Roxana-Maria Barbu. Her words and acts of support and encouragement made all the difference especially on days when completing my Master's felt impossible.

I would be remiss if I did not extend my thanks to Michael Dawson, whose undergraduate course, Foundations of Cognitive Science, and subsequent discussions were instrumental in my trajectory into this field of study. I would also like to acknowledge the financial support from the Social Sciences and Humanities Research Council.

Finally, I would like to thank my parents, Dora and Emmanuel Agyemang, for their sacrifices and their unwavering love and support. Thank you for teaching me to never be afraid to work hard. To my brother, Kofi, thank you for being an endless source of advice and humour. 


\section{Contents}

1 Introduction $\quad 2$

1.1 Informativeness and Probabilistic Inference . . . . . . . . . . . . . . . . 5

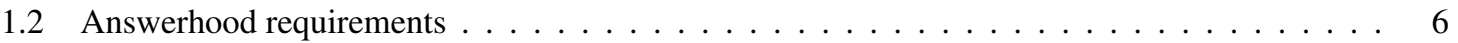

1.3 A note on the statistical analysis $\ldots \ldots \ldots \ldots \ldots$

2 Conversational Goals and Scalar Implicatures $\quad 12$

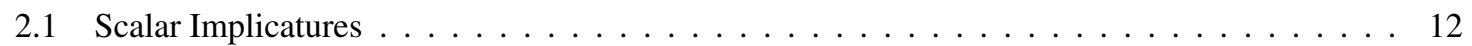

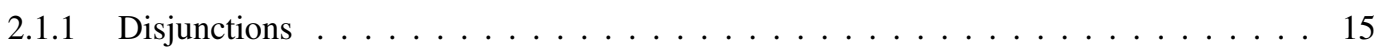

2.1 .2 Numerals ........................... 17

2.1 .3 Primary \& Secondary Implicatures . . . . . . . . . . . . . . . . . . . . 18

2.2 Conversational Maxims \& Scalar Implicatures _ . . . . . . . . . . . . . . . . . . . . . . 19

2.2.1 The Symmetry Problem . . . . . . . . . . . . . . . . . . . . . 21

2.3 Grammatical exhaustification . . . . . . . . . . . . . . . . . . 23

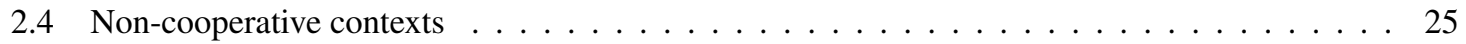

3 Cancelling the Maxim of Quantity 27

3.1 Implicature Cancellation . . . . . . . . . . . . . . . . . . . 27

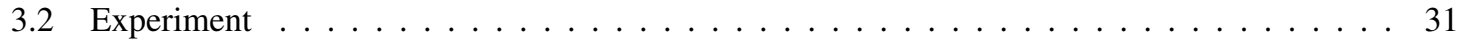

3.2 .1 Methods .......................... 31

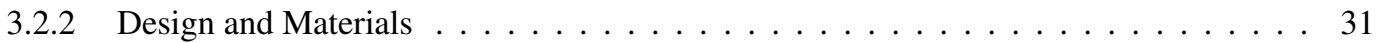

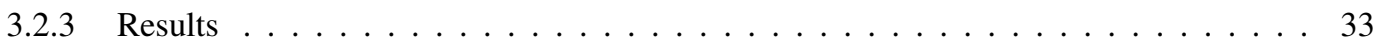

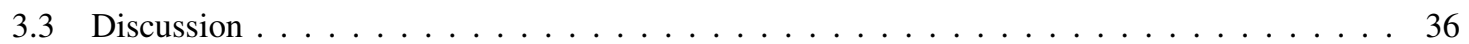


4 Implicature and Conjunction Errors $\quad 38$

4.1 The Linda Problem . . . . . . . . . . . . . . . . . . . . . . 38

4.2 Criticisms and alternative views . . . . . . . . . . . . . . . . . . . 42

4.3 Experiment $1 \ldots \ldots \ldots \ldots \ldots \ldots \ldots$

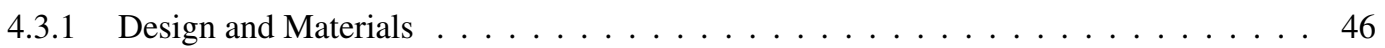

4.3 .2 Predictions ......................... 46

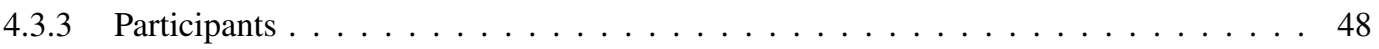

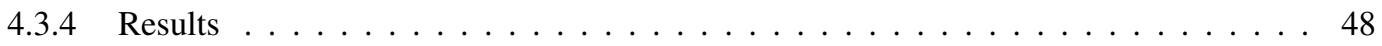

4.3.5 Individual differences in response strategy . . . . . . . . . . . . . . . . . . . 49

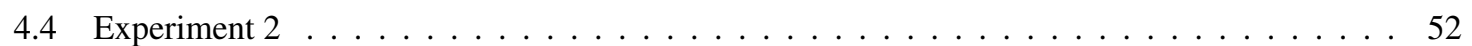

4.4 .1 Design and Materials . . . . . . . . . . . . . . . . . . 52

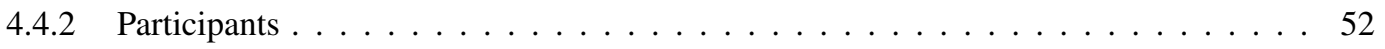

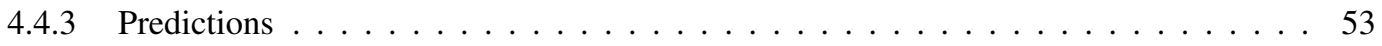

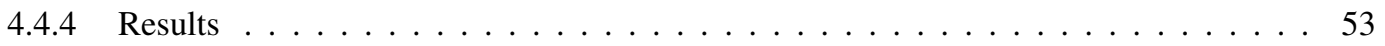

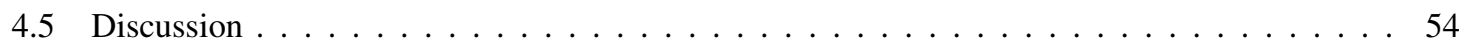

5 Hurford's Constraint and Natural Categories $\quad 5$

5.1 Hurford's Constraint $\ldots \ldots \ldots \ldots \ldots \ldots$

$5.1 .1 \quad$ Pragmatic Considerations . . . . . . . . . . . . . . . . . . 57

5.1 .2 Grammatical Constraints ........................ 61

5.2 Natural Categories . . . . . . . . . . . . . . . . . . . . 63

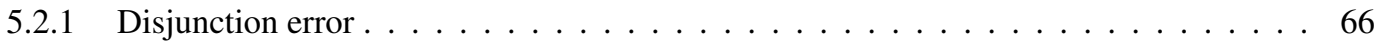

5.3 Experiment $1 \ldots \ldots \ldots \ldots \ldots$

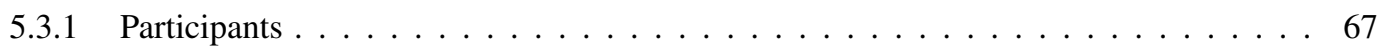

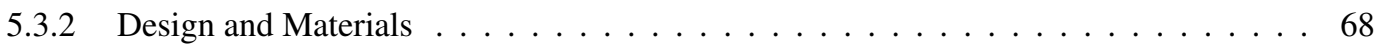

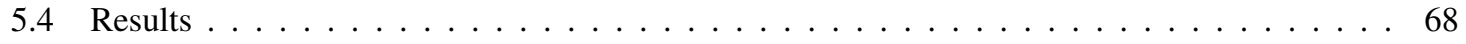

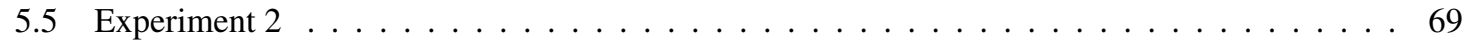

5.5 .1 Design $\&$ Materials ........................ 70

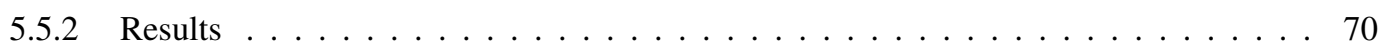

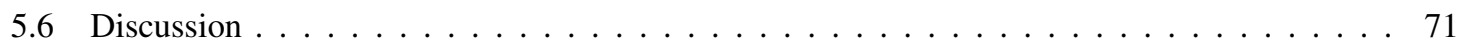


6 Conclusion

Bibliography 


\section{List of Tables}

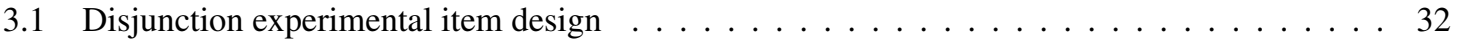

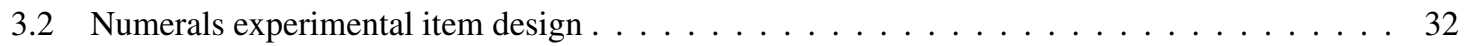

3.3 Predicted outcomes from pragmatic and grammatical frameworks for disjunctions . . . . . . 33

3.4 Response proportions and response times (s) with respective standard errors for each experi-

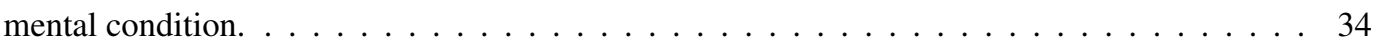

4.1 Key studies on the conjunction error $\ldots \ldots \ldots \ldots \ldots \ldots \ldots$

4.2 Sample item for original construction and disjunctive sentences of the Linda problem . . . . 46

4.3 Predicted outcomes for choices in each condition based on exhaustification . . . . . . . . . 47

4.4 Number of participants by response choices in conditions 2 and $3 \ldots \ldots \ldots$. . . . . . . 49

4.5 Number of participants in categorized by proposed response strategy. Note that the 2 participants that answered $p$ and $q$ in both conditions are not included because the effect may be negligible. . . . . . . . . . . . . . . . . . . . . . . 52

4.6 Sample item for relative rankings of propositions in the Linda Problem. . . . . . . . . . . 53

4.7 Mean and median values for relative rankings of propositions. Note that smaller values cor-

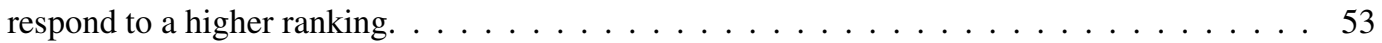

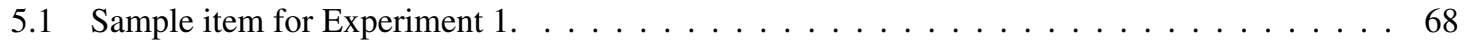

5.2 Sample item for Experiment $2 \ldots \ldots \ldots \ldots \ldots \ldots \ldots \ldots$

5.3 Mean and median values for relative rankings of disjunctions and filler items. Note that smaller values correspond to a higher probability ranking. . . . . . . . . . . . . . 70 


\section{List of Figures}

3.1 Pattern of response proportion as function of implicature availability and outcome. Error bars represent the standard errors of the mean. . . . . . . . . . . . . . . 35

4.1 Proportions of response choices for the conjunctive sentence or the alternative in each condition. The alternative in condition 1 was one of the two propositions in the conjunction $p, p$ or $q$ in condition 2 and $p$ or $q$ or both in condition $3 \ldots \ldots \ldots \ldots$

5.1 Proportion of responses for violations to Hurford's Constraint . . . . . . . . . . . . . . . 69 


\section{Chapter 1}

\section{Introduction}

Meaningful inferences involve a correspondence between the literal meaning of an expression and the communicative context in which it exists. The interpretation of literal expressions can be polysemous due to the varied contexts in which they can be applied. Thus, generating inferences requires a choice between relevant alternatives. This is dependent on what is said and what could have been said (Grice, 1975, 1989). Inferences can be characterized as answering a Question Under Discussion, which indicates that a declarative sentence is an answer to the meaning of a question (implicit or explicit) that is relevant to the conversation (Groenendijk and Stokhof, 1984; van Rooy, 2003a). For example, paraphrasing from Horn and Ward (2004), suppose that a hiring manager is asking their colleague about a prospective employee:

(1) HM: Is this person ambitious and loyal?

C: Well, she's ambitious.

Constructions such as (1) are ambiguous in their interpretations due to the uncertainty of what was left unsaid (is she loyal or not?). Intuitively, this omission implicates the colleague's belief that prospective employee is not loyal. The interpretation that the prospective employee is not loyal is known as the strengthened meaning as it is a stronger statement than was literally provided by the expression. It is a stronger statement in the sense that it is more informative to the Question Under Discussion. The interpretation that she is in fact loyal is the weak (or basic) meaning, as it is a more fundamental interpretation derivable from the literal expression. Specifically, the context and assumptions about the speaker's beliefs provide the necessary conditions for 
such an inference, yet, nothing about the prospective employee's loyalty is explicitly asserted.

Indeed, the coordination of an expression's literal meaning and its context prompts the derivation of a conversational implicature, which provides additional communicative meaning beyond what is literally said (Grice, 1975, 1989). Implicatures resolve the ambiguity by choosing the most likely interpretation from a set of candidate meanings of what a speaker intends to communicate ${ }^{1}$. Said differently, implicatures help to constrain the set of answers to a Question Under Discussion. Thus, implicatures can reduce the uncertainty and increase the informativeness associated with any particular answer.

That said, the circumstances and the requisite processes involved in generating an implicature are difficult to articulate, particularly in unconventional conversational contexts. Theories generally fall into two broad divisions: pragmatic (e.g., Gricean, neo-Gricean, Relevance-theoretic; Grice, 1975, 1989; Horn and Ward 2004; Sperber and Wilson, 1986) and grammatical (e.g., Chierchia et al. 2004, 2008; Fox, 2007). Pragmatic theories state that all types of implicatures result from the enrichment of the literal/semantic content of an expression. This enrichment occurs as a result of the Cooperative Principle: a presumption of a rational speaker's useful contribution towards conversational goals (i.e., communicating some information about the world). Grice describes the typical ways in which interlocutors engage in conversation to achieve such goals, particularly, how they reason about the communicated information through conversational maxims (Grice, 1975, 1989). The pragmatic framework stipulates that the conceptual burden of implicature rests on post-grammatical processes, leaving the semantics associated with making inferences relatively simple. The grammatical theories of implicature concede that while some implicatures do arise from conversational reasoning, others arise from language-specific mechanisms that emerge from parsing preferences.

Chapter 2 will outline the fundamental debate between pragmatic and grammatical theories through scalar implicature. Scalar implicatures are inferences that are strengthened on the basis of the quantity of information. Scalar implicatures are the result of (pragmatic or grammatical) exhaustification, which can be broadly defined as the exclusion of irrelevant alternatives. Consider (2) and (3):

(2) John will go to the bookstore or the record shop. $\Rightarrow$ John will go to the bookstore or the record shop but not both.

(3) She's three classes shy of graduating. $\Rightarrow$ She's exactly three classes shy of graduating.

\footnotetext{
${ }^{1}$ A note on the subtleties of the terminology used: implicature refers to meanings beyond literal meanings, inference refers to the cognitive processes applied by an individual to access an available meaning, and interpretation is a specific inference generated in a given context IGrice 1989. Horn and Ward 2004, Van Benthem 1987 and many others).
} 
In both (2) and (3) the implicatures limit the set of alternatives that can apply to the expression. In (2), the implicature negates the possibly that John will go to both the bookstore and the record shop. Likewise (3) excludes the possibility that she will need more than three classes (at least three) to graduate. Chapter 3 will empirically test predictions made by the pragmatic and grammatical theoretical accounts.

Chapters 4 and 5 will examine the relationship between weak and strengthened meanings in entailment relationships. Explicitly, they will investigate how manipulations of contextual relevance can either encourage or impede the generation of implicature. Chapter 4 will do so with a particular focus on conjunction. Consider (4):
a. I ordered soup.
b. I ordered soup and salad.

Expression $\mathrm{B}$ entails expression $\mathrm{A}$ if $\mathrm{B}$ is true, then $\mathrm{A}$ is true. For example, (4-b) entails (4-a). Under certain conditions, when a sentence B entails a sentence A, asserting A can generate an implicature about the information in sentence B that is false (Politzer and Noveck, 1991). For example, an utterance of (4-a) can license the implicature that (4-b) is false if (4-b) is relevant in the context in which A is uttered. The listener will infer from an utterance of (4-a) not only that I ordered soup, but also that I did not order salad.

Chapter 5 examines the comparison in category membership. Comparing (5-a) and (5-b):

a. He'll pick fruits from the orchard.

b. He'll pick apples from the orchard.

Similar to (4), the statements expressed in (5) are another comparison where one expression (5-b) entails the other (5-a). However, in this case, the implicature fruits and not apples is not intuitively generated from (5-a) being true. This is attributable to hierarchical nature of conceptual categories, where it is difficult to cross the boundary of the general class of fruit to specific kinds. This can be contrasted with (4) where the logical connective and can be used to compare the sentence in (4-a) with (4-b) to generate the implicature. Chapter 5 discusses and addresses this phenomenon, known as Hurford's Constraint, in further detail.

The availability of scalar implicatures in examples (4) and (5) is an important caveat for previous work on probability judgments. Using (4) again as an example, Tversky and Kahneman $(1974,1983)$ found that given a context that biases an individual to think I ordered salad, participants were found to rate soup and salad (4-b) more likely than soup alone (4-a). Under a basic interpretation, this violates the rules of probability 
(the likelihood of ordering soup on its own is greater than ordering both soup and salad) but as the example above demonstrates, one must consider the influence of implicatures on an individual's judgments. When (4-a) is interpreted to mean I ordered soup and not salad, then the choice of (4-b) does not violate probability theory. Interestingly, in (5), the same result has been shown, when given a context that biases apples over the general class of fruit, participants will more frequently rate He'll pick fruits from the orchard as more probable. This is particularly of interest, as previously mentioned, the implicature fruits and not apples is not readily available in most contexts.

\subsection{Informativeness and Probabilistic Inference}

This thesis aims to capture the nature of implicature empirically through probabilistic reasoning. Experimental research on the psychology of reasoning generally presumes that individuals interpret information under their basic meaning. The consequence of this presumption is that probability judgments derived from a basic interpretation of sentence are deemed as correct. When observed judgments deviate from the norms of probability theory, these judgments are viewed as errors in reasoning and are attributed to heuristics and cognitive biases. However, such studies fail to include how conversational reasoning can influence the interpretation of items presented in natural language. That is, it is possible that it is not basic meanings that enter into probabilistic judgments, but meanings strengthened with conversational reasoning, particularly scalar implicatures. Once this is taken into consideration probabilistic judgments no longer deviate from probabilistic norms. Here, I make the claim that judgments appear to deviate from probability only when scalar implicatures are available. I interpret this as evidence that human judgment obeys probability theory, and purported violations are actually instances where the meaning of the sentence is not the basic one but the one strengthened by implicature.

The permissible logical and pragmatic inferences in a given context will be evident from subsequent probability decisions. Practically, this will be a choice between the likelihood of alternatives, for example choosing between the statements in (5). This is motivated by the observation that the way we reason about language is intrinsically derived from the general way we reason about uncertainty (i.e., probabilities), as both involve a decision between alternatives based on their relative likelihoods and informativeness. In the experiments presented in this thesis, a given statement can correspond to one or more meanings that are available to 
a conversational participant. What is of interest is how individuals choose to resolve this ambiguity and the instances in which this ambiguity can be resolved structurally due to grammatical processes or contextually due to pragmatic processes.

Probabilistic choices between alternatives are well suited for probing the available inferences and response strategies. In most conversational contexts, the speaker intends to communicate information about some state of affairs through a conversational contribution. Therefore, the process of making an inference can represent the coordination between what a speaker intends as an interpretation based their contribution and what interpretation a listener happens to generate (Lewis, 1969). Importantly, here, the listener must reason why a speaker chose to communicate a given statement, and make use of this information in opposition to what could have been alternatively stated.

Using probability judgments as a measure of available and preferred inferences, I aim to determine both the interpretations that are available in principle to a listener and particular strategies that are employed by a listener in choosing to respond. To this achieve this, I will consider the relationship between entailment, implicature and informativeness and how it influences choices between alternatives.

\subsection{Answerhood requirements}

The relationship between scalar implicatures, inferences and the Question Under Discussion necessitates theoretical background on how questions are asked and answered. Broadly, theories about questions and answers aim to determine what constitutes a sufficient answer to a question and the necessary conditions for it to arise. Note that in this section, a "question" refers to an uttered interrogative statement and the Question Under Discussion is the meaning associated with the question. Recall that the Question Under Discussion generally refers to the implicit question that a conversational contribution answers. In the case of actual interrogatives, the Question Under Discussion is the semantic and pragmatic contribution that is intended by its utterance. There is usually a one-to-one correspondence between the interpretation of question that is asked and its Question Under Discussion, however, this distinction is an important one. Such concepts focus on characterizing the role of questions in communication and their contributions to the conversation. Key attempts made in articulating the question-answer relations and the requirements for answerhood will be described here. 
Belnap and Steel (1976) identifies three components to a so-called direct answer, specifically, one that sufficiently answers the Question Under Discussion: the selection and selection size, the completeness claim and the distinctiveness claim. The selection is the answer chosen by the listener (right or wrong) that resolves the question. The selection size optimizes speaker and listener economies, where the speaker asks the question in a way that either explicitly or implicitly presents a reasonable number of alternatives for a listener to choose from. The authors base this hypothetical number of alternatives on utility theory, which measures the value associated with the number of alternatives that increases before reaching a plateau (1976 p. 40). This is primarily based on the notion that a speaker is looking for an answer to a question that they are not certain about. Said differently, it is presumed that the speaker formulates the question in such a way that is feasible for the listener to answer.

The completeness claim denotes the amount of information required to choose an answer. A maximum completeness claim specifies that a selected answer must be inclusive to all of the possible answers in the selection. For example, the question "What are the even numbers between 1 and 9?", a maximum completeness claim would require a selected answer of $\{2,4,6,8\}$. A partial completeness claim requires that some value out of the set of possible answers are in the selection. For example, "What are some capital cities in Canada?", only necessitates a certain proportion. In addition, an empty set claim specifies that direct answers need not make any completeness claims.

Lastly, the distinctiveness claim stipulates that each alternative be a uniquely distinct member of that selection. Repeating the example from Belnap and Steel (1976, p. 61) "What are at least five examples of prime numbers?" a non-distinctive answer is $\{2,5,7, \mathrm{VII}\}$, where 7 and VII share the same interpretation.

Groenendijk and Stokhof (1984) regard this criteria as being too restrictive to the ways that conversational participants can answer questions, noting that the sufficiency of an answer will depend mainly on the prior information that the questioner has. At the same time, they do agree that an answer as a resolution to a Question Under Discussion ought to be exhaustive (complete to the desiderata of the question). This is also reflected in Hamblin's (1958) description of answerhood, such that, the meaning of an interrogative is marked by the set of propositions that provide an exhaustive resolution to the question. In other words, knowing what constitutes a sufficient answer to the question is a description of the meaning of the question itself. This is also an identification of the Question Under Discussion. Groenendijk and Stokhof (1984) specifically adopt partition semantics which specifies the question-answer relationship as one that requires exhaustive answers, 
or answers that completely address a Question Under Discussion. This notion of exhaustivity is known as a mention-all interpretation (Groenendijk and Stokhof, 1984; van Rooy, 2004).

van Rooy (2004) points out a challenge to partition semantics in that questions can instead be ambiguous in their intended meanings and in subsequent interpretations. This ambiguity can be represented by mentionsome and mention-all interpretations. A mention-some interpretation states that an exhaustive (maximally complete) answer is not required by the intended meaning of the question. Explicitly, a partial answer to a Question Under Discussion would sufficiently answer it. Consider the question in (6):

Where can I buy some persimmons?

Under a mention-some interpretation, "Farm Boy" as an answer resolves the question, without requiring an exhaustive list of all the possible places to buy persimmons. van Rooy (2003b, 2004) goes on to assert that contextual strengthening resolves the ambiguity of the question itself. The context resolves the meaning of the question, and by consequence allows an individual to choose the best answer to address the given interpretation of the question, rather than assuming a standard interpretation and choosing the "best" alternative of that (van Rooy, 2003b). In contrast to Hamblin's (1958) description that knowledge of the answer set is equivalent to the knowledge of the question, van Rooy and Van Rooij and Schulz states that when the set of alternatives to a question is specified, it can give insight to the interpretation of the question asked by the speaker (2003b; 2004). This point is pertinent to Hurford's Constraint which I will describe in Chapter 5

This is point is also relevant for scalar predicates where there is a difference between the upper and lower bound associated with the scalar item and the resultant implicature. Paraphrasing the example by Dekker et al. (2007), consider someone asking about driving speeds:

a. How fast can you drive in the neighborhood?

b. How slow can you drive on the freeway?

Both of the questions in (7) could have the same literal answer, say 50 kilometres per hour, however the implicature is different in the two cases. In (7-a) the implicature is no more than $50 \mathrm{~km} / \mathrm{h}$, which further indicates that the intended question is one with respect to the maximum speed. Whereas in (7-b) the implicature is no less than $50 \mathrm{~km} / \mathrm{h}$, which suggests that the intended question is one with respect to the minimum speed. An unanswered issue is under what circumstances exhaustivity can be attributed to the semantic and pragmatic processes, respectively. 
The types of pragmatic and contextual constraints that are required in question-answering can be attributed to the Gricean maxims of Quality, Quantity and Relevance (Groenendijk and Stokhof, p. 26). A selected answer satisfies these maxims if it is: (i) true, (ii) the best answer given that it is true and (iii) contains no or the least amount of irrelevant information. Under these maxims, Groenendijk and Stokhof determine a preference ordering to answers to a question. Specifically, where complete answers are generally preferred over partial ones, alternatives that are answers are preferred to ones that give answers, (ones that require additional inference), and that pragmatic answers are more important than semantic ones. Here, a pragmatic answer is one that takes into account the conversational context and makes assumptions on the informational states and beliefs of a questioner. Moreover, contextual parameters also influence how a question is interpreted and thus answered. Consider examples from Roelofsen (2019, p. 10) adapted here in (8):

a. Which students cheated on the final?

b. What is the winning card?

c. Who is driving to the party tonight?

d. Where is the Queen of England?

(8-a) refers to a determination of the set of interest, specifically, which students out of all possible students does this question refer to. More generally, the question is interpreted with a particular set of members in mind. (8-b) refers to the method of identification for identification questions (marked by what; Aloni, 2005). The interpretation of the question will depend on the questioner. In one case, a dealer can ask a contestant to choose one of the cards and the answer resolves the question by making a choice. Alternatively, if the questioner is a player confirming the rules, the answer in (8-b) has a different referent (e.g., Queen of Clubs). The method of identification has been identified as the observation that meaning arises out of the questioner's act of asking the question (Beck and Rullmann, 1999). (8-c) relates to the mention-some and mention-all distinction, where a non-exhaustive answer may be acceptable to the question. In (8-c) if the questioner doesn't know all of the people who are invited to the party, then an exhaustive answer is not necessarily useful. Lastly, (8-d) denotes the level of granularity, where the precision needed for a sufficient answer can vary in different contexts. Specifically for (8-d), the answer The Queen of England is in London may be sufficient for general knowledge, whereas the Queen's security guards may need to know in which room in Buckingham Palace she is currently in. 
Thus, a formalized theory of answerhoood depends on an understanding of the semantic and pragmatic mechanisms involved in selecting an answer, particularly in terms of exhaustification. An important caveat of this review is that these processes are largely concerned with cooperative conversation, in that, it is assumed that the interlocutors share the same goals and intentions with respect to the conversation. The answerhood requirements may differ in non-cooperative contexts, for example in situations of opponents playing against each other. Chapter 2 will describe at length how scalar implicature can facilitate selecting the answer to the Question Under Discussion in cooperative contexts. The availability of inferences in non-cooperative contexts will be additionally considered.

Generally, in this thesis, I will adopt the notion of logical partitions to describe how a set of propositions can be asserted or negated. For example, the proposition $p$ can either be true or false, creating a binary partition of logical space $\left\{p, p^{\prime}\right\}$. A practical example of this is the question Is the birthday cake ready?, which can be affirmed (yes) or denied (no).

\subsection{A note on the statistical analysis}

Whenever appropriate, this thesis uses mixed effects models to analyze the data ${ }^{2}$. The primary advantage to mixed effects modelling for linguistic data is that it allows the statistical analyses to account for the uncontrolled (random) variability that is associated with factors in the design outside of the experimenter's manipulation (Baayen et al., 2008). The two common sources of randomness in an experiment are participants and experimental items. In terms of participant variability, there is randomness associated with the sample of the participants who are selected for the study. This can have consequential influences on the effects under examination, especially for response times, where some participants may be slower or faster to respond. This variability is generally accounted for by collecting a large sample of participants in the study. However, for items, a large number of items can lead to response fatigue or may make a covert experimental manipulation more evident to a participant. When larger sample sizes are not feasible, mixed models can account for variability associated with random factors by including the effects of random factors on the slope and the intercept of the model, also known as the random effects structure. Linear, logistic and ordinal mixed effects regression models are used in this thesis to analyze the effects of response time, response choice and

\footnotetext{
${ }^{2}$ All data and analysis files are available on the Open Science Framework: https://osf.io/rkmp9/ and can be accessed upon reasonable request.
} 
response ranking respectively. To determine what the effect of interest is in each case, the mixed effects model will be minimally dissociated, using a likelihood ratio test, with a model that does not include the effect (e.g., main effect of a variable, interaction between two variables). 


\section{Chapter 2}

\section{Conversational Goals and Scalar}

\section{Implicatures}

This chapter will review the literature on scalar implicature as a phenomenon with a focus on disjunctions and numerals. Following this, the two broad schools of thought on scalar implicatures: the pragmatic framework (Grice 1975, 1989; Horn, 1972; Geurts, 2009; van Rooy, 2003a; Sauerland, 2004 and many others) and the grammatical framework (Chierchia et al., 2004, 2012; Noveck et al., 2002; Fox, 2007; Fox and Katzir, 2011 and the like) will be described and subsequently compared in their predicted inferences.

\subsection{Scalar Implicatures}

Implicature, introduced in the seminal work by Grice, articulates that there is implicit information communicated in conversation beyond what is explicitly said $(1975,1989)$. The derivation of an implicature is contingent on what has been explicitly said in the exchange. Scalar implicatures can provide information about the quantity of information that a speaker can (or is willing) to communicate to a listener in conversation. Consider the example in (9):

(9) John ate some of the cookies.

This statement implicates that John did not eat all of the cookies. This implicit understanding is mainly 
derived from the meaning of some, which can be defined as a scalar term (i.e., a lexical item representing a quantity). Horn (1972) defines scales of informativeness on which these lexical items exist, where, some exists on the scale of $<$ few, some, many, most, all $>$, ranked from least to most informative (see Levinson 1983, p. 134 for a comprehensive list). In this particular instance, all is more informative than some as all entails some as an expression. Strength is synymous with informativeness, where all can be described as a stronger term than some. Explicitly, given $\psi=$ John ate all of the cookies, the statement $\phi=$ John ate some of the cookies would necessarily be true, and crucially, the opposite does not hold. On the basis of rationality, if the speaker was aware that John ate all of the cookies (as an alternative to some of the cookies), it would be more useful to the conversation to say that John ate all of them. Therefore, it is generally assumed that scalar implicatures are generated in comparison to alternative statements that the speaker could have possibly said based on the information available to them (Horn, 1972; Grice, 1975).

Scalar implicatures are also dependent on the restriction on the number of possible alternatives or exhaustification. This is based on the notion of informativeness (no two items should be equally as informative) and patterns of monotonicity/entailment (Horn, 1972). Particularly, Atlas and Levinson (1981) assert that the items in a scale i.e., $\langle\psi, \phi\rangle$, must share the same degree of lexicalization and belong to the same semantic field. Gazdar (1979) states that a scale must be generated based on a set of entailment relationships, based on pragmatic ordering rather than semantic (literal) ordering, as entailment relationships can change depending on context. Hirschberg broadened this scope beyond alternatives that exist in an entailment relationship to any items that can form a partially ordered set, where order predicates (higher/lower/alternate) can be determined between instances of the set, such as ranking ordering (see Hirschberg, 1985, 1991 for full characterization). Here, entailment is a special case of the ordered relation between items in a set. Additionally, she mentions that items in a given scale must be in some way "salient", or rather, one particular item has to be more informative to implicate the negation of another.

Returning to (9), by saying some, the implicature is that the speaker negates the truth of any stronger scalar term (John did not eat all of the cookies). This is the strengthened meaning of the proposition, which refines the interpretation of some to its upper bound, as in (10).

John ate some but not all of the cookies.

Example (11) demonstrates that scalar implicatures can also be cancelled in conversation without contradic- 
tion, simply by asserting the stronger term (Grice, 1975; Horn and Ward, 2004). Grice (1975) characterizes implicature cancellation as a fundamental aspect of scalar implicature (and conversational implicatures more generally), distinguishing it from entailments.

John ate some and possibly all of the cookies.

Further to this point, Grice claims that cancellability is a necessary but not sufficient aspect of implicatures, whereby if an utterance is non-cancellable, it is not a implicature. However, if it is cancellable then further analysis is required to determine if it is an implicature. The cancellability of implicatures has been subject to debate. Skepticism includes implicatures that also exist in entailment relationships (Bach, 2006; Carston, 2004; Sperber and Wilson, 1986), the speaker's intentions, specifically, if an utterance is said with the particular intention to generate an implicature then it cannot be cancelled (Capone, 2009, 2010), and cases that are resistant to cancellation such as sarcasm and irony (Huitink and Spenader, 2004; Weiner, 2006). See Zakkou (2018); Haugh (2013) for an overview/defense of the cancellability criterion.

Yet, in some contexts, a scalar term may not generate an implicature at all and retain its so-called basic meaning (also referred to as the weak/logical/literal meaning), which allows for the entailment of the stronger scalar term. Paraphrasing from Kearns (2011):

The photographer wants some of the cast members for a group picture.

Example (12) can be understood to mean that the photographer wants some and possibly all cast members to be present for the picture. More generally, it can be said that scalar terms represent a choice between a basic (weak/literal/logical) interpretation and its strengthened (strong/pragmatic) interpretation. Theoretical frameworks differ on how basic and strengthened meanings are derived with a broad division between formmeaning pairs. Such that, there is disagreement on whether a proposition with a scalar term is ambiguous between its basic and strengthened meanings or if each interpretation is independently accessed based on contextual demands. Related to this is the observation that scalar implicatures do not affect the truth conditions of the sentence, where the literal content (basic meaning) of the sentence does not depend on the truth of the scalar implicature (Grice, 1989). Looking again to (9) and related examples, it is necessarily true that John ate some of the cookies, regardless of whether he did or did not eat all of the cookies.

A fundamental challenge for linguistic theories is articulating the criteria and circumstances wherein a scalar implicature is most likely to be generated. The following sections will briefly outline two cases of 
scalar implicature of particular interest: disjunctions and numerals.

\subsubsection{Disjunctions}

Disjunctive sentences or disjunctions (this or that) describe partial knowledge between two or more alternatives (disjuncts), specifically asserting that at least one alternative is true in the world. Disjuncts inform listeners that the speaker is not certain of which of the disjuncts is true, otherwise the listener would expect the speaker to simply assert one disjunct over the other, or assert that both disjuncts are true. Logical disjunction represents an inclusive disjunction (this or that, or both), which permits that either one or both of the disjuncts are true. This is often described as "and/or". This is illustrated by Noveck et al. (2002, p. 298) which is repeated in (13):

$$
\text { An applicant should have a degree in engineering or } 5 \text { years of related experience }(\Rightarrow p \vee q) \text {. }
$$

However, the use of the connective "or" in natural language can also be strengthened to an exclusive interpretation, where only one of the disjuncts are true (i.e., this or that, but not both). A scalar implicature generated as a result of disjunction is known as the exclusivity implicature. This is often described as "either/or". For example.

(14) John is a university professor or a government official. $(\Rightarrow p \oplus q)$.

Longstanding questions for the scalar implicatures in disjunctions are under what circumstances will a listener interpret a disjunction either as inclusive or exclusive, and are there global preferences for one over the other? While example (13) licenses the interpretation of having both an engineering degree and 5 years of related experience, example (14) can be interpreted as a choice between alternatives. This is particularly salient in cases of mutual exclusivity, where it can be deduced that both disjuncts cannot be true at the same time, thereby negating the conjunctive alternative, $p \wedge q$ (e.g., He is in New York or in Los Angeles).

Chierchia et al. (2004) and Noveck et al. (2002) state that an inclusive interpretation of a disjunction can occur in any context where or can be interpreted as any, otherwise known as free choice disjunctions. Using another example from Noveck et al. (2002, p. 303):

Do you have a pen or a pencil?

Here, the interpretation Do you have any of the following: pen, pencil is available, such that, it wouldn't 
be odd for an interlocutor to reply "Yes, I have a pen or a pencil, in fact I have both". Further to this point, the authors argue that examples like (15) favour inclusive interpretations because they are downward entailing contexts, drawing from Ladusaw (1980). Downward entailing contexts occur where the scope of information about a set also holds for its subset (e.g., if none of Professor X's graduate students attended the lab meeting, then it is also necessarily true that none of Professor X's doctoral students attended the lab meeting). Specifically, in (15) the inclusive interpretation, $p \vee q$, can be more informative than the exclusive interpretation, $p \oplus q$. Therefore, as in (15) if the speaker is looking for any writing utensil, then the optionality of both is more informative to the question than exactly one or the other. To better illustrate informativeness in inclusive disjunctions, there are some instances that are marked by a quasi-conjunctive free choice reading (Nickel, 2010) such as in (16):

Elephants live in Africa or Asia.

Where the use of or can be used to distinguish African Elephants and Asian Elephants as different species. Here, it is presumed that and would yield the interpretation that it is the same type of elephant that exists in both Africa and Asia (Meyer, 2018). Therefore, this preference may partially be related to the class-inclusion relationships of the disjuncts.

Exclusivity has been cited as being more likely to be used in ordinary discourse (Fillenbaum, 1974). Yet, studies on the computation of disjunctions found that inclusive disjunctions are often computed first before strengthened to an exclusive interpretation (Bott and Noveck. 2004; Breheny et al., 2006), more easily accessed under cognitive load (De Neys and Schaeken, 2007), preferred in constructions of arbitrary items (e.g., letter and word strings; Evans and Newstead 1980) and when there is equivalence between an inclusive and exclusive interpretation (Braine and Rumain, 1981). Furthermore, children generate an inclusive interpretation more readily than the exclusive counterpart (Singh et al., 2016; Noveck, 2001; Tieu et al., 2015). These experimental findings lend credence to the notion that the basic meaning of a disjunction is computed first then later revised to a strengthened meaning. This is finding also true of certain other scalar terms (e.g., some; Bott and Noveck, 2004; Chemla and Spector, 2011). 


\subsubsection{Numerals}

Numerical expressions or numerals denote a quantity (e.g., three, four). Similarly to disjunctions, it has been remarked that a given numerical expression "three", for example, is ambiguous between a basic meaning of at least (lower bound) three and exactly three (upper bound), although there is debate about how these readings come about (Spector, 2013; Horn and Ward 2004). The ambiguity is the result of the numerals not being qualified by any other expression (i.e., three instead of at most three). This is known as a bare numeral. Consider the following examples adapted from Spector (2013):

a. Stephen has four children.

b. In order to become a lifeguard, Maria has to pass two certification exams.

In (17-a), the sentence allows the scalar implicature exactly four, under the expectation that if the speaker knew that an alternative sentence was in fact true (i.e., Stephen had five children), they should simply say that number instead. In (17-b), an at least two reading is computed, particularly, in comparison to the alternative - that Maria will not become a lifeguard if she takes more than two classes (under an exactly two reading).

Numerals also present a challenge for generalizability of theories of scalar implicature, as they behave differently in empirical findings compared to disjunctions and other such scalar terms (e.g., <some, all >), where the basic meaning is easier to acquire, process and retrieve. Studies investigating numeral scalar implicatures consistently find that the strengthened meaning (exactly) is strongly preferred (Marty et al., 2013; Papafragou and Musolino 2003). This has prompted some theorists to infer that for numerals, individuals default to an exactly reading and then revise it to an at least reading in necessary contexts (Breheny, 2008; Geurts, 2006). Indeed, the Defaultist theory of scalar implicature argues that the general derivation of scalar implicatures is automatic and effortless, and instead the cancellation of the implicature is costly (Grodner et al., 2010; Feeney et al., 2004).

Additionally, in comparison to disjunctions and other scalar terms, numerals have been shown to be preferred in circumstances where the numbers of the set are easy for an individual to reason with (within the subitization range; Degen and Tanenhaus 2015), while other scalar terms (e.g., some) were dispreferred in the same contexts. This has been attributed to be the result of maximizing informativeness, where a specific number is more informative than a generalization of a quantity (two vs. some). 


\subsubsection{Primary \& Secondary Implicatures}

Scalar implicatures can be further categorized into primary and secondary implicatures. Pragmatic theorists have used this distinction to respond (theoretically and empirically) to criticisms. At this level of granularity, the difference between the processes involved in the pragmatic and grammatical frameworks becomes more evident. Consider (18):

(18) Maria found some of the Easter eggs.

a. The speaker is not sure that Maria found all the Easter eggs.

b. The speaker is sure that Maria didn't find all of the Easter eggs.

(18-a) represents the primary scalar implicature, such that, the hearer reasons that the speaker is not opinionated about the stronger statement (all). This explanation is consistent for both pragmatic and grammatical frameworks to scalar implicature. The secondary scalar implicature in (18-b) and its computation have been contrastively characterized by the pragmatic (mainly neo-Gricean views) and grammatical frameworks. Namely, the pragmatic framework states that the secondary scalar implicature is directly derived from the primary scalar implicature on the basis of the opinionatedness criterion (also known as the competence assumption, Van Rooij and Schulz, 2004; experthood assumption Sauerland, 2005; and authority assumption Geurts, 2010). Sauerland (2005) describes the derivation of the secondary scalar implicature from the primary scalar implicature as the epistemic step, based on what a hearer believes about a speaker's knowledge. Notably, the listener reasons that because the speaker did not assert the stronger claim, they must not believe that it is true. For the example in (18) it is presumed because the speaker does not say that Maria found all of the Easter eggs, that they are opinionated that she did not.

The grammatical framework states that secondary scalar implicatures are the result of grammatical exhaustification (Fox, 2007; Chierchia et al., 2008), and are thus not dependent on the primary scalar implicatures. In support of this view, Dieuleveut et al. (2019) determined that secondary scalar implicatures remain available when the competence assumption does not hold ${ }^{1}$

\footnotetext{
${ }^{1}$ These results were also consistent with predictions from a game-theoretic approach to scalar implicature, which relies on higher order reasoning about an individual's beliefs IGoodman and Stuhlmüller 2013. Bergen et al. 2016!.
} 


\subsection{Conversational Maxims \& Scalar Implicatures}

Under the pragmatic (Gricean, Neo-Gricean, Relevance-Theoretic) views, the Cooperative Principle is a prerequisite for scalar and other such related implicatures (Grice, 1975, 1989; Atlas and Levinson, 1981; Horn and Ward, 2004; Levinson, 2000; Matsumoto, 1995; Sperber and Wilson, 1986 and many others). The Cooperative Principle regards conversational exchange as cooperative, where the participants are rational and have a mutual understanding of the purpose and direction of the conversation (Grice, 1975, and others). Therefore, it is assumed that each participant will make a contribution that adheres to the established purpose of the given exchange. Arising from the Cooperative Principle are maxims of conversation, which denote how interlocutors are expected to behave in cooperative contexts. The conversational maxims are: Quality, Quantity, Relation and Manner. Respectively, each describe that a participant's contribution to the conversation should be truthful, concise, relevant, and clear. Implicatures generally arise from the expectation that the speaker is following conversational maxims and their subsequent sub-maxims.

Recall that scalar implicatures are fundamentally derived from the presumption that a speaker denies a stronger claim than what is literally said (i.e., in the sense of Horn scales, where or is less informative than and $(<$ or, and $>))$. According to the pragmatic views, scalar implicatures are derived from the maxim of Quantity, which is concerned with the quantity of information communicated by a speaker. Quantity stipulates that, speakers should make contributions which are maximally informative to the purpose of the conversation. Two sub-maxims that are derived from Quantity are:

1. Make your contribution as informative as is required for the purposes of the conversation.

2. Do not make your contribution more informative than is required.

Scalar implicatures are therefore derived from obeying Quantity-1 in conversation, as the listener assumes that the contribution is maximally informative and thereby denying more informative contributions.

The maxim of Quantity is also paralleled in the economy of linguistic information.(Zipf, 1949; Horn and Ward, 2004). Zipf describes that language and other human behaviours operate on the Principle of Least Effort, where communicative efforts are optimized to be minimally effortful on the behalf of the donor and simultaneously maximally informative to a recipient. Related to the Principle of Least Effort, Quantity's two sub-maxims invite listeners to derive the required implicatures to fully understand the message without the speaker having to add in unnecessary information. Horn motivates this by adopting Zipfian notions of com- 
munication effort/efficiency, in what he denotes as Q and R-principles (2004) and argues that conversational maxims can be reduced to these two principles. The Q-principle is fundamentally derived from Quantity-1 and is concerned with information sufficiency. The R-principle is derived from the Principle of Least Effort, and concentrates on the minimization of form. Horn ties these two principles to certain pragmatic phenomena, namely, the observation that lexicalized, ubiquitous and shorter constructions are typically the result of the R-principle, and that unique and particularized expressions can be attributed to the Q-principle. Consider (Horn and Ward, 2004, p. 16):

a.) My brother went to jail. (R)

b.) My brother went to the jail. (Q)

Where (18-a) refers to the generalized meaning of being sentenced to jail and in (18-b) it is presumed that the brother went to a specific jail institution, not necessarily as a result of a crime.

Quantity can also interact with other Gricean maxims through the generation of scalar and other conversational implicatures. In particular, Quantity often interacts with the maxim of Quality, which states that one's contribution to the conversation should be truthful. Two sub-maxims that arise from this are:

1. Do not say what you believe is false.

2. Do not say what you do not have evidence for.

As a result of the two Quality sub-maxims and Quantity, different conversational implicatures can be computed by a listener. One under Quality-1, which presumes that the listener denies knowledge about a stronger claim (a so-called ignorance implicature), and another under Quality-2, where the listener denies knowledge (or belief) about the truth of a stronger claim (scalar implicature) (Gazdar, 1979; Atlas and Levinson, 1981). An example by Grice (1989, p. 37) is repeated here to describe the computation of a scalar implicature under Quality-2, which will become especially pertinent later into this chapter.

(20) A is planning with B an itinerary for a holiday in France. Both know that A wants to see his friend $\mathrm{C}$, if to do so would not involve too great a prolongation of his journey:

A: Where does $\mathrm{C}$ live?

B: Somewhere in the South of France. 
B's answer violates Quantity because it is less informative than is required for the purpose of the conversation, however, this can be explained under Quality-2 (B speaking to the extent of their knowledge). This is known as an ignorance implicature (inference), which implies that the speaker is ignorant, or rather, not opinionated about the stronger claim (in the preceding example, B is ignorant about where in the South of France C lives). Here, the expectation that Quantity applies is suspended (not expected but not explicitly cancelled in the discourse) in favour of preserving Quality. Quality is arguably the most fundamental of the conversational maxims as it cannot be suspended/cancelled to preserve any of the other three maxims (Grice 1975; Matsumoto, 1995; Harnish et al., 1976).

\subsubsection{The Symmetry Problem}

As mentioned in the Introduction, the Question Under Discussion is a (often implicit) question that is answered by an asserted statement in the conversation. The Question Under Discussion is constrained by the particular intentions of the conversational participants and the nature of the conversation itself. For example, if the asserted statement is Susie was late, this could be the answer to two different Questions Under Discussion and can consequently yield different pragmatic results. Specifically, if the Question Under Discussion was Who was late? then Susie was late is likely to generate the strengthened meaning that Only Susie was late. If the Question Under Discussion was Was Susie on time?, the answer implicates that No, Susie was late (Van Rooij and Schulz, 2004). Zondervan et al. (2008) finds experimental support that indicate the Question Under Discussion influences the types \& likelihood of implicatures generated by a statement.

The Question Under Discussion is generalizable to the Questions and Answer Requirement (Gualmini et al., 2008; Singh et al., 2016)). The Question and Answer Requirement states that participants following the Cooperative Principle will seek out a complete answer to a question. Recall that what constitutes a complete answer and the overall answerhood of Questions Under Discussion is a (often exhaustive) list of relevant predicates. A complete answer not only sufficiently addresses the Question Under Discussion, but also provides insight on the relative status of the alternatives, in the sense that selecting one answer should negate the truth of the other alternatives (Groenendijk and Stokhof, 1984; Roberts, 1996). As stated by partition semantics, a Question Under Discussion, an answer and its alternatives can be represented by cells in a partition of logical space (van Rooy, 2003a). For example, given the choice between two propositions (e.g., cake and ice-cream), p, $q$, each proposition can be asserted or negated, summarized as: 
$\left\{p q, p^{\prime} q, p q^{\prime}, p^{\prime} q^{\prime}\right\}$

Consequently, a partial answer such as $p \vee q$ (cake or ice-cream), eliminates at least one cell of the partition, $p \vee q$ rules out $p^{\prime} q^{\prime}$ (neither cake nor ice-cream). A complete answer would be choose a particular cell from the partition such as $p q$ (cake and ice-cream). Scalar implicatures strengthen partial answers provided by a literal reading of the statement, as in (9), to a complete answer to the question (10). As previously mentioned in Section 2.1, the computation of a scalar implicature is contingent on the listener considering the scalar alternatives (e.g., some vs. all) that the speaker could have asserted but chose not to. Thus, the alternatives that could address a Question Under Discussion are considered to be relevant to the asserted statement. However, the intuitive appeal of the relevance of alternatives becomes problematic when considering statements that easily generate a scalar implicature such as (9). This is referred to as the symmetry problem (von Fintel and Heim, 1985). To characterize the symmetry problem, (9) is repeated here as (22) for convenience.

$$
\phi=\text { John ate some of the cookies . }
$$

The alternative sentence that the speaker could have asserted is, $\psi=$ John ate all of the cookies, As the speaker did not assert this, under Quantity, the listener generates the scalar implicature $\neg \psi=$ John ate not all of the cookies, and strengthens the meaning to $\gamma=$ John ate some but not all the cookies, thereby negating $\psi$. The trouble arises from considering the negation of $\psi$ (represented as $\gamma$ ) as relevant because then $\psi$ must also be a relevant as answer to the question of how many cookies John ate. Here, the pragmatic views predict that both $\psi$ and $\gamma$ are equally likely implicatures from $\phi$, hence symmetry. Explicitly, both are equally informative as an answer to the question of what John ate. When the speaker asserts $\phi$, it is assumed that it is the only proposition that the speaker is certain of. The speaker is therefore ignorant about the stronger claims, otherwise, under Quantity, the speaker ought to assert one of the more informative alternatives $\psi$ or $\gamma$ if they believed either to be true. This gives us the resultant circumstances:

1. $\psi$ is available, yet it was not asserted, therefore $\gamma$.

2. $\gamma$ is available, yet it was not asserted, therefore $\psi$.

However, only one statement is acceptable, as, $\phi \wedge \neg \psi$ and $\psi$ are scalar alternatives (Fox and Katzir 2011). Ultimately, it cannot be both true that John ate some but not all of the cookies ( $\gamma)$, and John ate all of the cookies $(\psi)$, but both can be derived from John ate some of the cookies $(\phi)$. While there is an 
intuitive prediction that $\gamma$ is the obvious choice for the implicature, there are no aspects in a traditional Gricean characterization of scalar implicatures that can account for why $\gamma$ is preferred to $\psi$.

Neo-Gricean approaches have responded to the symmetry problem by stating that one does not need to consider all alternatives as relevant and restricting the scope of alternatives to only those that exist in a formal set (e.g., Horn Scales). This eliminates $\gamma$ as a possible alternative, and results in the options between strengthened meaning $\phi \vee \neg \psi$ and alternative $\psi$ (Sauerland, 2004). However, Katzir (2007) and Fox and Katzir (2011) show that resolving the symmetry problem using a formulation on the basis of Horn scales, which argues that the some but not all alternative is not lexicalized as scalar term, is not successful. It also has consequences for ignorance inferences. The neo-Gricean approaches argues that both ignorance and scalar implicatures are the result of Quantity, where the hearer assumes that the speaker is opinionated about the alternative, specifically that it is false $(\neg \psi)$. Appeals to preserving the maxim of Manner at the expense of Quantity (i.e., the speaker chooses $\phi$, rather than presumably $\gamma$ or possibly $\psi$ to be concise rather than maximally informative) have equally been subject to criticism (see for Breheny et al. 2018 for a comprehensive review of the approaches to the symmetry problem).

Generally, the pragmatic views assert that conversational implicatures are always derived from pragmatic mechanisms. In other words, a complete answer is the result of the literal meaning, context and conversational goals and maxims. Thus, in pragmatic characterizations of implicatures, it is presumed that a semantic/compositional meaning is first established and is then later globally enriched through said pragmatic mechanisms (Potts, 2015; Grice, 1975; Gazdar, 1979; Matsumoto, 1995). This will be contrasted with grammatical framework in the next section, which can arguably account for some of the data that the pragmatic views cannot.

\subsection{Grammatical exhaustification}

In contrast to the pragmatic framework, which considers scalar implicatures to be the result of meeting conversational demands/goals, the grammatical framework indicates that scalar implicatures are derived from grammatical operations that resolve ambiguity between a sentence's basic and strengthened meaning. An analogous division exists between what meaning is computed compositionally, as a result of the syntactic and semantic structures and associated meaning, and postcompositionally, through pragmatic strengthening 
in context (Noveck et al., 2002; Chierchia et al., 2012; Chemla and Singh, 2014a b). Chierchia et al. (2004) proposed that there is a silent exhaustify operator $O$ (similarly depicted as $e x h)$ which is akin to the lexical item only that strengthens/constrains the meaning of a scalar term. The exh operator is known for its optionality, meaning that the sentence can be parsed with or without it, explaining cases such as (12) where a strengthened meaning isn't computed. This process is known as grammatical exhaustification and is the result of the recursive process of semantic processing (Chierchia et al., 2008, 2004).

Looking once again to (9) and related examples from a grammatical perspective (Singh, 2019, p. 2):
a. John ate some of the cookies $(\phi)$
b. John ate some but not all of the cookies $(\phi \wedge \neg \psi)$

The grammatical framework would predict the following operations to strengthen the meaning. A listener generates $A L T(\phi)=\{\psi\}$, which identifies the alternatives to the asserted statement $(\phi)$. Then exh is applied to compute the meaning $O(A L T(\phi))(\phi)=\phi \wedge \neg \psi$. exh applied on (23) results in John only ate some of the cookies. Here, the output is the result of the permissible operations allowed by the language system and the negation of contextually restricted alternatives.

Another major difference between the pragmatic and grammatical frameworks to scalar implicature is the scope in which the scalar implicature can be derived. The pragmatic framework assumes that scalar implicatures are derived globally, meaning that implicature is the result of a speaker's intended meaning at the level of speech acts. Conversely, the grammatical framework can apply exh operator at the sentence and sub-sentence levels in what is known as embeddedness.

Local embeddedness can be characterized as the syntactic operator exh being applied systematically to the local context in which it is most relevant. Consider Chierchia et al. (2012, p. 2313):

a. Mary solved the first problem or the second problem or Mary solved both problems.

b. Mary solved the first problem or ${ }^{1}$ the second problem (or both) ${ }^{1}$ or $^{2}$ Mary solved both problems $(\text { or both })^{2}$.

The basic meaning of (24) is made explicit in (b). Under most pragmatic views, the speaker ought to interpret (24) as:

(Mary solved the first problem or the second problem, or both) or (Mary solved both problems), but 
not both.

Evidently, this is redundant because the first clause is entailed by the second. Assuming that scalar implicatures are the results of the entire meaning of a conversational contribution, there are therefore no aspects of the pragmatic view that can account for recursive computations of scalar implicatures at a sub-sentence level. The grammatical framework can rectify this by applying a exh operator to the first clause as well as the entire sentence. The grammatical interpretation of (24) can be summarized as:

$$
\operatorname{exh}(\alpha \vee \beta) \vee \gamma
$$

Local embeddedness has been supported by experimental findings (see Chemla and Spector, 2011). Conversely, Geurts and Pouscoulous (2009) demonstrate the opposite findings where scalar implicature does not always occur in embedded positions (see Clifton Jr and Dube, 2010 for continued debate).

Using exhaustification, the grammatical view can also account for the symmetry problem mentioned in Section 2.2.1 (Fox and Katzir, 2011; Fox, 2007). Fox and Katzir state under this framework the exh operator will strengthen the meaning (see previous discussion in (23)). To elaborate, the exh operator negates any alternatives that are stronger than the one derived from the addition of only to the meaning (i.e., John ate all of the cookies; Horn, 1972; Singh, 2008; Van Rooij and Schulz, 2004; Hirschberg, 1985).

Nevertheless, the grammatical framework is not without its points of contention and criticism. Singh (2019) outlines some of the challenges to the grammatical framework on the basis of exhaustification/strengthening. Specifically, that the grammatical framework cannot account for conflicting data from different types of scalar implicatures. As previously mentioned, the basic meaning in disjunctive sentences are more easily retrieved, yet we see the opposite empirical findings in numerals. The preference for the strengthened meaning in numerals is counter-intuitive to the grammatical framework which presumes that there is additional cognitive effort as a result of applying exh. Singh therefore proposes a domain-theoretic approach based on representational complexity (by way of Boolean complexity and semantic automata) to account for both results.

\subsection{Non-cooperative contexts}

Gricean theories state that implicatures result directly from adherence to the Cooperative Principle and its subsequent maxims. By consequent, Gricean pragmatics only makes predictions about their availability in coop- 
erative contexts. Grice himself notes that interlocutors can participate in conversation in non-cooperative and deliberately uncooperative ways (e.g., lies or misleading information; Grice, 1975, 1989). Non-cooperative contexts can be described as conversations where interlocutors may share the same conversational goals but one does not fully adhere to Gricean maxims in their conversational contributions. Uncooperative contexts are those in which interlocutors do not share the same conversational goals, and these goals can even be in opposition. Some have argued that even participating in conversation requires a minimum level of cooperation, where one responds to their conversational partner (Geurts, 2009). More specifically, interlocutors may differ on their level of cooperation. One issue for theories of implicature that appeal to Gricean maxims is that there is no account of a hearer's expectations in non-cooperative contexts. This raises the questions about the available inferences when the cooperativity of one's conversational partner is under scruntiny.

Behavioural experiments on the availability of scalar implicatures in uncooperative games (where opponents play against another) determine that while implicature can still be generated in these contexts, they occur significantly less so than in cooperative contexts (Pryslopska, 2013; Dulcinati and Pouscoulous, 2016). Interestingly, in Pryslopska's (2013) study, using the scalar item some and eye-tracking data, she found that individuals were generating the scalar implicature and then quickly cancelling it. To this effect, Asher and Lascarides (2013) state that the difference between so-called Gricean cooperativity and non-cooperative contexts is not the availability of the implicature simpliciter, but instead how reliable an individual feels the information conveyed by the implicature is on behalf of the speaker. Dulcinati and Pouscoulous (2016) used disjunctions and found a reduced number of implicatures in uncooperative contexts. However, their experimental design did not allow them to determine if participants were generating the implicature then subsequently cancelling or not generating it at all. It is of interest to examine these effects in other scalar items, particularly when considering the general differences in cooperative contexts when processing scalar implicatures, where they appear to be accessed first in numerals and accessed only after a revision to the literal meaning in other scalar terms. 


\section{Chapter 3}

\section{Cancelling the Maxim of Quantity}

Pragmatic and grammatical theories of implicature disagree on whether scalar implicatures arise from the adherence to the maxim of Quantity or to structural processing through grammatical exhaustification. The necessity of Quantity as a requisite condition for generating scalar implicatures can minimally dissociate between the two frameworks. This chapter will describe and empirically test Fox's (2014) hypothetical game-show scenario, where the speaker need not obey Quantity (i.e., communicate all the information that is relevant to the conversation).

\subsection{Implicature Cancellation}

In Grice's (1975) formalization of the Cooperative Principle, participants can opt out of the principle and its subsequent maxims. This can be achieved by simply stating that they will not be cooperative towards the goals of the conversation (e.g., one refusing to disclose information because they were sworn to secrecy). When the speaker is not expected to be fully informative, for example, in the context of a treasure hunt, the grammatical and pragmatic frameworks predict that ignorance inferences would not be generated (Fox, 2014; Grice, 1975, 1989; Sperber and Wilson. 1986; Levinson, 2000). Using the example of a treasure hunt, the listener would not necessarily know if the speaker was ignorant about where the treasure is buried, it could reasonably be that the speaker does know but will not disclose this information based on the rules of the treasure hunt. The listener cannot justifiably generate the inference that the speaker is ignorant about where 
the treasure is hidden. An ignorance inference can even be explicitly cancelled, as Grice points out, if the speaker were to say that they do know where the treasure is but for the purpose of the game, they won't tell their conversational partner this information $(1975 ; 1989)$. To this end, Fox (2014) theorizes on the effect that cancelling Quantity has on the types of inferences that a listener can generate from the conversation.

The objective of Fox's (2014) thought experiment on cancelling Quantity is to demonstrate the difference in how grammatical and pragmatic frameworks account for circumstances when a speaker does not need to communicate all the information relevant to the conversational goals. As Gricean maxims are only described in cooperative contexts, pragmatic frameworks in general cannot make any predictions as to why scalar implicatures are conceivably still available when Quantity is deactivated. ${ }^{1}$. To further dissociate between the two views, Fox presents a hypothetical game show scenario, where there are five boxes out of a hundred that have a million dollars inside. The game show host knows which boxes have money inside of them but mentions that they will not explicitly tell the contestants this information, thereby cancelling the ignorance inference. The host will provide the contestant with some hints/partial information to help them make a choice. Fox illustrates one potential round of the game show (p. 12):

There is money in box 20 or 25 .

The scalar implicature in (27) would be that there is money either in box 20 or there is money in box 25 , but not both. An inclusive interpretation is also available and could possibly arise given the parameters of the game (under the presumption that Quantity is cancelled), such as in (28):

There is money in box 20 or 25 or both.

The grammatical frameworks predicts that scalar implicature should be available despite Quantity being deactivated as scalar implicatures occur at the semantic level rather than pragmatic, through the application of exh:
a. $p \vee q$
b. $\operatorname{exh}(p \vee q)$
c. $(p \vee q) \wedge \neg(p \wedge q)$

\footnotetext{
${ }^{1}$ This statement primarily applies to pragmatic frameworks that adopt a less granular view of the semantics associated with generating scalar implicatures (see Westera 2020 and sections 3.3 and 5.1.1 for more context).
} 
Under the pragmatic frameworks, on the other hand, implicatures are derived from conversational maxims. Since the maxim of Quantity is deactivated in the context of a game show, the pragmatic frameworks do not make any predictions as to why the listener is still able to conclude that there is money only in box 20 or only box 25 from (27). Based on the assertions made from such views, Fox derives the prediction that for the pragmatic views there should not be any difference in interpretation between (27) and (28). Under these views, both (27) and (28) represent an inclusive interpretation of the disjunction under the pragmatic constraints. While both Gricean and neo-Gricean views suggest that only an inclusive interpretation is available, Gricean pragmatics observe only the adherence to the Maxim of Quantity, whereas neo-Gricean frameworks modify the criterion, such that, the Maxim of Quantity applies only to a set of formally restricted alternatives (e.g., Horn scales (Horn, 1972) or structural alternatives (Fox, 2007)). Recall from Chapter 2 that this is the neo-Gricean response to the symmetry problem.

Again, these predictions oppose what can be predicted by the grammatical frameworks. Fox further motivates this by demonstrating that it is acceptable for a contestant to refute that there is money in both box 20 and 25 when given (27) as a hint, where exclusivity is available and it is odd to refute this when given (28) as a hint where it is not.

Fox's original characterization only includes disjunctive statements, however, in this thesis, I aim to extend this line of reasoning to numerals, especially since the scalar implicatures that arise from numerals are demonstrably salient and preferred in some contexts (Papafragou and Musolino, 2003; Marty et al., 2013). Consider (30):

a. There is money in one box.

b. There is money in exactly one box.

c. There is money in at least one box.

A strengthened reading as in (30-b) would be a precise answer to the Question Under Discussion of how many boxes contain a million dollars. This should be greatly preferred to a basic reading as in (30-c). Going further, it is likely that a strengthened meaning derived from a scalar numeral as in (30) compared a disjunctive sentence (27) is more useful to a contestant in this scenario. It would be more informative to know that there is exactly one box that contains a million dollars than to known that either box 20 or box 25 but not both have a million dollars. 
All this being said, Meyer et al. (2013) argues that it is unnecessary to state that Quantity is cancelled in a game show scenario. Repeating Quantity-1 here for convenience, Grice states "Make your contribution as informative as is required for for the purposes of the conversation". Providing all of the relevant information to the contestant about where the money is would defeat the purpose of the game. Therefore, Meyer argues Quantity-1 accounts for circumstances outside of cooperative conversation. She also demonstrates that Fox's game show scenario can be used to defend against the claim that Quantity-2 (Do not make your contribution more informative than is required) and the claim that the maxim of Relevance are redundant, as mentioned by Horn and Ward (2004). If the host is aware of which boxes have money, telling a contestant this as a stronger alternative is certainly relevant to the conversation, yet for the purposes of the game, is more informative than necessary.

Nevertheless, Meyer still found that the pragmatic frameworks have difficulty to account for the scalar implicature. The non-assertion of either disjunct (e.g., box 20, box 25) is attributed to Quantity-2, where asserting either disjunct (e.g., there is money in box 20) would be a stronger statement than the current conversational goals. This cancels the ignorance inference, as it is uncertain that the speaker is ignorant about which box has money or that the speaker will not disclose this information. If neither disjunct can be asserted, then their conjunction (the money is in box 20 and box 25) also cannot be asserted. Difficulty arises because the non-assertion of the conjunction results from the constraints of the game show scenario, rather than belief that the truth of the stronger conjunctive statement does not hold, which would typically be used to generate the scalar implicature (not both in this case). The pragmatic frameworks still cannot account for why the scalar implicature should be available in the game show scenario. To rectify this as well as caveats with respect to the grammatical framework, the author proposes a third framework based of Matrix K Theory (see Meyer et al., 2013 for a full description).

To reiterate, when Quantity is unavailable we have competing predictions: (i) under the pragmatic frameworks, scalar implicatures are deactivated when Quantity is cancelled and (ii) under the grammatical frameworks, scalar implicatures are in principle available as an inference even when Quantity is cancelled. These predictions have yet to be tested empirically. This section aims to investigate this using Fox's game show paradigm for disjunctive statements and numerals. 


\subsection{Experiment}

Presently, I adapted Fox's (2014) game show scenario in order to dissociate between the competing views on the nature of scalar implicature by identifying the grammatical and pragmatic processes involved in its computation. The debate concerning scalar implicatures largely considers contexts where conversational participants are assumed to be maximally informative (i.e., are not withholding any information). What remains unclear is what would occur when a conversational participant is not required to disclose all their relevant information.

\subsubsection{Methods}

\subsubsection{Participants}

Two hundred and ten participants were recruited either as volunteers from a community sample or as undergraduate students from the Carleton University undergraduate research pool (SONA). Volunteers received an invitation to the study shared via social media and did not receive any compensation for their participation. Undergraduate participants received partial course credit (0.25\%) in an introductory Cognitive Science course. The study was approved by the Carleton University Research Ethics Board.

\subsubsection{Design and Materials}

I adapted Fox's game scenario paradigm, using a 2(Implicature Availability) X 2(Previous Outcome) X 2(Scalar Item) within-subjects design, where the participant saw a disjunction or a numeral that either licenses or cancels a scalar implicature. Participants saw four disjunctive sentences and four numerals ${ }^{2}$. Additionally, the participant was informed of the approximate likelihood associated with a particular answer based on the host's hint and the outcome (winning or losing) from a previous contestant.

Response counts and response time data (in seconds) were collected. No additional information (e.g., age, gender and other demographics) were collected from the participants of the study. See Tables 3.1 and 3.2 for item design. The full set of experimental items can be found in Appendix A. Response time data was comprised of the time to fully read the scenario and make a decision about which alternative is more likely.

\footnotetext{
${ }^{2}$ The numerical expressions were constrained to a choice between only two possibly relevant alternatives to be comparable to the disjunctive statements and to make the other alternative particularly salient.
} 
Table 3.1: Disjunction experimental item design

Your task is to choose a numbered box. There are 100 numbered boxes in total and five of them contain a million dollar prize. The host tells the first contestant that there is money in box 20 or box 25/box 20 or box 25 or both. This contestant picks box 20 and finds a million dollars there/ discovers that the box is empty. Imagine you are the next contestant in this game. The host does not give you any new hints. Which action are you most likely to take?

a.) Choose box 25 .

b.) Choose another box.

Table 3.2: Numerals experimental item design

Your task is to choose a numbered door. There are eight numbered doors and four of them are associated with a million dollar prize. The host tells the first contestant that there is money associated with one/at least one door with a number less than 3 . The contestant before you picks Door 1 and wins a million dollars/does not win any money.

Imagine you are the next contestant in this game. The host does not give you any new hints. Which action are you most likely to take?

a.) Choose Door 2 .

b.) Choose another door.

\subsubsection{Predictions}

For the response times, the results may be consistent with the respective literature on numerals and disjunctions. Namely, the basic interpretation in disjunctions will be faster to process compared to its strengthened counterpart (Noveck, 2001; Tieu et al., 2015). For numerals, the opposite finding could arise, where the strengthened meaning would be more easily accessed to the basic counterpart (Papafragou and Musolino 2003; Marty et al., 2013). However, empirical data is lacking on the time course of scalar implicature when conversational maxims do not apply. Similarly, they may be emergent patterns as a result of one of the alternatives being asserted or negated (e.g., faster responses times when the previous contestant won after picking a given box), although what they might be is unclear.

Under the pragmatic framework, there should be no difference between inclusive and exclusive disjunctions as scalar implicatures are wholly unavailable. Under the grammatical framework, the prediction is that there should be an interaction between the implicature (whether it is available or cancelled) and the previous outcome (winning or losing). Specifically, when the previous contestant did not win any money, participants 
ought to choose the salient alternative (i.e., box 25) regardless of whether the implicature is licensed or cancelled, based on the host's hint. However, when the previous contestant did win money, participants under the condition where the implicature is licensed (box 20 or box $25 \Rightarrow$ but not both) should not choose the alternative and instead choose another box. When the implicature is cancelled (box 20 or box 25 or both) and the previous contestant did win money, participants should be more likely to choose the alternative given as a hint, as in this case having a million dollars in box 20 does not negate that there is also money in box 25 . Table 3.3 outlines the experimental conditions and their predicted outcomes under the competing frameworks.

Table 3.3: Predicted outcomes from pragmatic and grammatical frameworks for disjunctions

\begin{tabular}{cccc}
\hline Framework & Disjunction & Previous Outcome & Predicted Choices \\
\hline Pragmatic & box 20 or 25 & won & another box $\approx$ box 25 \\
& box 20 or 25 or both & won & another box $\approx$ box 25 \\
& box 20 or 25 or both & lost & box $25>$ another box \\
box 20 or 25 & lost & box $25>$ another box \\
\hline Grammatical & box 20 or 25 & won & another box $>$ box 25 \\
& box 20 or 25 or both & won & another box $\approx$ box 25 \\
& box 20 or 25 or both & lost & box $25>$ another box \\
& box 20 or 25 & lost & box $25>$ another box \\
\hline
\end{tabular}

For the condition in bold, the pragmatic and grammatical frameworks differ in their predicted choices based on a question of implicature availability. While only the predictions for the disjunctions are presented here, the same logic applies for numerals. Specifically, when there is money in one of two options (e.g., door 1 or door 2) and the previous contestant won, the pragmatic framework predicts that a specified alternative (e.g., door 2) and the choice for "another option" (e.g., another door) from the sample should be equally likely. The grammatical framework instead predicts a preference for another option over the specified alternative, due to the availability of the implicature exactly one.

\subsubsection{Results}

\subsubsection{Descriptive Statistics}

Extreme outliers were identified using the boxplot method and further corroborated using the interquartile range. Outliers were trimmed from the dataset before subsequent analysis. Table 3.4 denotes the mean proportions of responses for the alternative given in the experimental item (e.g., box 25) and the mean response 
times per experimental condition. Higher responses corresponded to more choices for the specified alternative and lower responses indicate more choices for "another option".

Table 3.4: Response proportions and response times (s) with respective standard errors for each experimental condition.

\begin{tabular}{ccccc}
\hline Scalar Item & Implicature & Previous Outcome & Proportions (SE) & RT (SE) \\
\hline Disjunctions & Available & Won & $0.22(0.05)$ & $32.1(1.6)$ \\
& Available & Lost & $0.82(0.05)$ & $27.4(1.5)$ \\
& Unavailable & Lost & $0.86(0.04)$ & $29.2(1.5)$ \\
& Unavailable & Won & $0.39(0.06)$ & $33.6(2.0)$ \\
\hline \multirow{6}{*}{ Numerals } & Available & Won & $0.26(0.06)$ & $31.0(1.8)$ \\
& Available & Lost & $0.86(0.04)$ & $28.5(1.8)$ \\
& Unavailable & Lost & $0.81(0.05)$ & $27.8(1.4)$ \\
& Unavailable & Won & $0.44(0.07)$ & $33.1(1.7)$ \\
\hline
\end{tabular}

\subsubsection{Inferential Statistics}

Response Times. Response times were collected as the total time for the participant to read the context and make a response to the question of interest. As response times are often right-skewed, they were transformed to a logarithmic scale to approximate normality and were subsequently analyzed using a linear mixed model with the "Imer" function from the "Ime4" package in R (Bates et al., 2015). Implicature availability and prior outcome were coded as fixed effects. Based on recommendations by Barr et al. (2013), a maximal random effects structure was used, specifically a model that included the maximum random effects that did not fail to converge. The random structure adopted a per-participant random adjustment to the fixed outcome intercept $(S D=0.13, r=-0.21)$. Additionally, the fixed effect of outcome was included to the random slope term. Item as a random effect was not included in the structure as it had a low variance and would fail to converge or overfit the data when added as to the formula. A likelihood ratio test determined that there was significant main effect of prior outcome $\left(\chi^{2}(1)=16.06, p<0.0001\right)$. This main effect demonstrates that when the response times were collapsed across conditions of implicature availability and type of scalar item, if previous contestant won, participants were on average four seconds slower to respond (32.1s) than if the previous contestant lost $(28.1 \mathrm{~s} ; \beta=-0.13, t=-4.04, p<0.0001)$. The $p$-value was adjusted using the Tukey method to correct for multiple comparisons. There was no influence of the type of scalar item (disjunction or numeral) on the response time $\left(\chi^{2}(1)=2.62, p=0.11\right)$. Likewise, there was no main effect of implicature $\left(\chi^{2}(1)=0.76, p=0.38\right)$. 
Looking at the relationship between response times and response choices, while not significant, a linear regression suggests a general trend $(\beta=0.22, t=0.82 p=0.41)^{3}$. Participants were slightly faster to choose the given alternative (29.1s) compared to choosing another option (31.4s). This effect arose independently of the effects prior outcome, type of scalar item or the availability of the implicature.

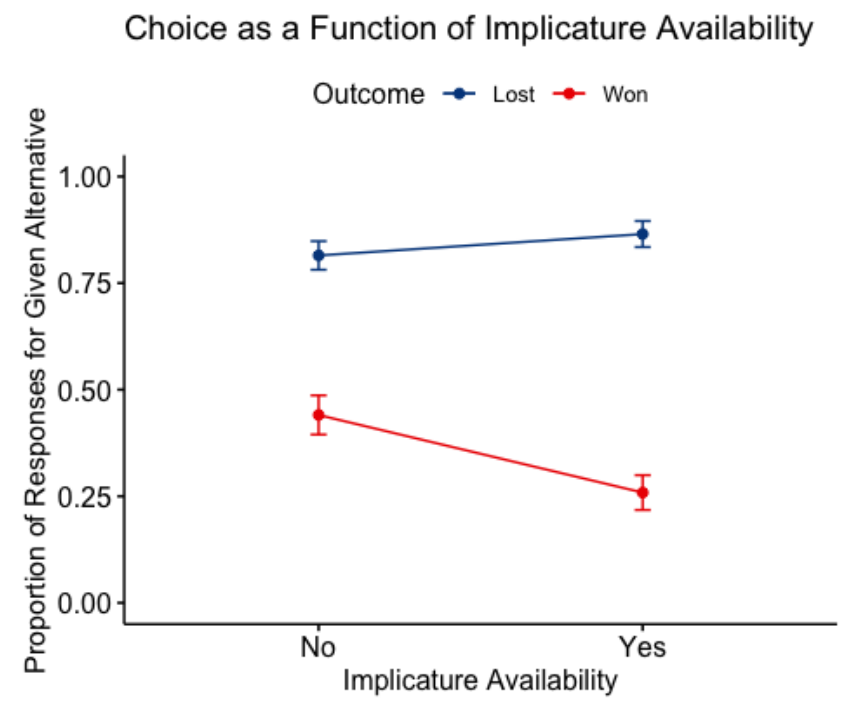

Figure 3.1: Pattern of response proportion as function of implicature availability and outcome. Error bars represent the standard errors of the mean.

Response Counts. Figure 3.1 illustrates the pattern of results for the response counts. Response counts for both disjunctions and numerals were analyzed using a logistic mixed model with the 'glmer" function from the "Ime4" package in R (Bates et al. 2015). Implicature availability, type of scalar implicature and previous outcome were coded as fixed effects. Similarly for the random effects structure used for the response times, the model used a per-participant random adjustment to the fixed outcome intercept and outcome has added as a fixed effect to the random slopes $(S D=1.73, r=-0.98)$. Overall, there was a significant two-way interaction between previous outcome and implicature availability, as determined by a likelihood ratio test $\left(\chi^{2}(1)=5.93\right.$, $p<0.015$ ). When the previous contestant won and the implicature was unavailable (box 20 or 25 or both) participants were more likely to choose the specified alternative (box 25) than when the implicature was available (box 20 or 25 , but not both; $\beta=0.84, z=2.88, p=0.021$ ). When the previous contestant did not win money, participants strongly preferred the specified alternative regardless of whether the implicature was

\footnotetext{
${ }^{3}$ Random effects were not included in this analysis to avoid overfitting the data.
} 
available or blocked ( $\beta=-0.38, z=-0.93, p=0.79$; Tukey adjusted). Again, there was no influence of the type of scalar item (disjunction or numeral) on the response choices $\left(\chi^{2}(1)=1.53, p=0.22\right)$. This is the pattern of results that was predicted by the grammatical framework. The pragmatic framework predicted a main effect of outcome with no interactions, which would have been represented by two parallel lines with greater values when the previous contestant lost and smaller values when the previous contestant won.

\subsection{Discussion}

The results of this study are consistent with the predictions of Fox (2014) under the grammatical framework to scalar implicature, where, scalar implicatures remain available under circumstances where Quantity is not active. This current study shows that when a scalar implicature is in principle available to a listener (e.g., box 20 or box 25) that individuals generate scalar implicatures to strengthen the meaning of a sentence. As a manipulation check, when the previous contestant lost, the predictions from either theoretical framework state that participants ought to choose the specified alternative, regardless of whether the implicature is available or not. Generally, participants chose responses consistent with this prediction, with higher proportions of choices for the specified alternative compared to the choice of another option.

Response times also support this, such that, participants were quicker to respond to an item when they are told that the participant previously lost than when they won. Response choice were not influenced by the type of scalar implicature (disjunction/numeral). There were no difference in response times for choosing the specified alternative compared to another option. This result does not support the prediction that response times would be faster for those who did not generate the scalar implicature in disjunctions and faster for those who did generate them in numerals. This effect is partially attributable to the experimental design, as the response time included the time to read the scenario and then respond to the question. This metric is likely not to be precise enough to capture the respective processing mechanisms of disjunctions and numerals.

One limitation of the study is that it was administered as a within-subjects design where participants saw conditions in which the implicature was available and in which the implicature was not. A potential consequence of this is that the participants were comparing the difference between the plain disjunction or numeral (e.g., box 20 or 25) with such items that cancelled the implicature (e.g., box 20 or 25 or both). This comparison may have prompted individuals to generate the scalar implicature independently of Quantity 
being cancelled. This could be further exacerbated by the general tendency of individuals to interpret what is implicated as being what is true (Larson et al., 2009). Thus a between-subjects design should be conducted to provide additional support for the current findings. Additionally, the use of Hurford's disjunction to cancel the implicature presents a challenge to what can be expected as a prediction, particularly from the neoGricean views. Here, the disjunction "box 20 or 25 or both" is presumed to be equivalent to "box 20 or 25", irrespective of cancelling the maxim of Quantity (Alonso-Ovalle, 2006 and see Meyer, 2014 for further discussion). This observation presents added considerations for the feasibility of the neo-Gricean views of scalar implicature outside of ideal contexts. The notion of Hurford's constraint and disjunctions will be further described in Chapter 5.

Another consideration is that while this study primarily considers Gricean and neo-Gricean views as representative of the pragmatic frameworks, there are other pragmatic frameworks that make use of a semantics where "A or B" is not equivalent to "A or B or both", for example, attentional pragmatics (Westera, 2018a), which states that "A or B" implicates not both based on Relevance as a maxim and general concept instead of Quantity. Predictions under such an account would be identical to the grammatical framework. Thus further studies should investigate the difference between such an approach and the grammatical frameworks empirically. Additionally, the results do not explicitly confirm that participants are deriving the scalar implicature under grammatical exhaustification. As exh here is presumed to be optionally applied (Chierchia et al. , 2004 2008), there is no specification as to how it is generated when Quantity is cancelled and other non-cooperative contexts. More broadly, this investigation points to a further required consideration of the pragmatic conventions and expectation that may persist and arise in non-cooperative contexts. The present study and others (e.g., Dulcinati and Pouscoulous, 2016) demonstrate one phenomenon, where scalar implicatures can arise in contexts were the speaker is non-cooperative or deliberately uncooperative (in competition with a listener). 


\section{Chapter 4}

\section{Implicature and Conjunction Errors}

The conjunction error is defined as a misjudgment of probabilistic reasoning where one representative event can bias individuals to rank the conjunction of that event and another as more likely than another event on its own. Specifically, when given a contextual description of "Linda" that is prototypically representative of a feminist, participants are more likely to chose the statement "Linda is a bank teller and a feminist" compared to the statement "Linda is a bank teller". Criticisms have challenged this notion by arguing that the comparison between an event and the conjunction of the event and another is pragmatically odd, as it compares the set to its subset. This chapter demonstrates that using a similar entailment between a disjunction (Linda is a bank teller or a feminist) and the conjunction significantly reduces the number of conjunction errors committed. Thus, participants are sensitive to the pragmatic circumstances of the conjunction error. Additionally, a comparison between plain disjunctions and disjunctions that only allow for an inclusive interpretation shows no difference in response patterns. A secondary analysis of the data suggests particular response strategies that participants may adopt with respect to implicature generation and probability judgments.

\subsection{The Linda Problem}

In their classic investigations on judgments under uncertainty, Tversky and Kahneman $(1974,1983)$ argue that individuals use cognitive heuristics to help them to make probabilistic decisions. Cognitive heuristics can be defined as "rules of thumb" or generalized patterns that individuals use to facilitate inferences and to 
make decisions. Heuristics are desirable as they are less cognitively expensive and more often than not will yield the correct results (Stanovich and West, 2000; Kahneman, 2003). One of the most well-documented heuristics used in probabilistic judgments is the representativeness heuristic. The representativeness heuristic states that an instance that is more representative of the schematic representation of an event will be judged as more probable, regardless of the actual statistical probability of said event occurring (e.g., a robin is a highly representative instance of a bird and would therefore be more judged as a more probable instance of the bird category). Representativeness can be understood as the relative correspondence between an outcome (e.g., instance, prediction, result) and the model (e.g., event, category). Perceived likelihood of an outcome is influenced by the relationship between the model and a particular outcome and can be judged based on aspects such as similarity or availability (as with the robin example). The representativeness heuristic is derived from the observation that instances that are more typical of category/event tend also to be more frequent occurrences in that category (Tversky and Kahneman, 1983; Kahneman et al., 1982). While heuristics are an effective cognitive strategy, Tversky and Kahneman, among others, argue that in certain circumstances it can bias individuals to incorrect conclusions. This is demonstrated by the Linda problem created by Tversky and Kahneman (1983, p. 297):

Linda is 31 years old, single, outspoken and very bright. She majored in philosophy. As a student, she was deeply concerned with issues of discrimination and social justice, and also participated in anti-nuclear demonstrations.

Which of the following is more probable?

a. Linda is a bank teller $(\mathrm{T})$.

b. Linda is active in the feminist movement $(\mathrm{F})$.

c. Linda is a bank teller and is active in the feminist movement (T\&F).

In their original 1974 study (reprinted in 1982 and replicated in their 1983 study), Tversky and Kahneman included these three choices as part of a larger list of possible alternatives (e.g., Linda is a preschool teacher) that participants had to rank in order from most to least probable. Predictably, (31-b) was rated more probable than both (31-a) and (31-c). The crucial finding is that, on average, participants were apt to mistakenly rate (31-c). as more probable than (31-a) given the description. This finding is known as the conjunction error. Probability theory states that the probability of a conjunction of two events is necessarily less than the 
probability of one of the conjunctive alternatives (conjuncts) on their own. With respect to our example, the set of bank tellers is necessarily larger than the set of bank tellers and feminists, as the set of bank tellers is inclusive to both those that are and are not feminists. Tversky and Kahneman conclude that individuals make this fallacious judgment as a result of the representativeness heuristic (the so-called representativeness hypothesis) since the given description makes "feminist" incredibly salient, further evidenced by the relatively higher ranking of 2 .

Tversky and Kahneman (1983) find further evidence to support their representativeness hypothesis, as they find that conjunctive errors are virtually eliminated when a nondescript version of the Linda problem is given, although this finding is contested in related studies; (c.f. Stolarz-Fantino et al., 2003). They attribute this result to the fact that the instance of "Linda is a (bank teller) and feminist" in this case is no longer representative of the overall category of feminists.

This conclusion is further supported by Wells's (1985) subsequent study on the effect of representativeness on the likelihood of committing the conjunction error. Here, Wells compares the relative effect of representativeness based on the perceived relationship of each conjunct to the reference category. Specifically, he adapted the Linda Problem for three conditions: (i) where one of the conjuncts was representative and the other was unrepresentative of a broader category, (ii) where both conjuncts were unrepresentative and (iii) where both conjuncts are representative. In (i), Wells replicated the conjunction effect, and unsurprisingly in (ii) the conjunction effect was virtually eliminated as both conjuncts did not reflect the category of interest. The compelling finding is that the conjunction effect was attenuated when both conjuncts were representative of the category. Wells speculates that occurs because a single representative event evokes a particular sample space for participants to predict relevant probabilities, whereas the sample space of joint probabilities might be harder to reason with.

The prevalence of the conjunction error is also influenced by the presentation of the problem. Hertwig and colleagues demonstrate that they can prompt a statistical interpretation of likelihood by framing the probability judgment in terms of frequencies. For example, "given the description of Linda, describe the number of women in a population of 100, who are bank tellers/bank tellers and feminists?'. In this design, the relative amount of conjunction errors was significantly reduced (Hertwig and Gigerenzer, 1999; Fiedler 1988) Gigerenzer argues that the conjunction error is reduced in a frequency format because individuals tend to represent probabilistic information in terms of frequencies (Gigerenzer, 1994). This is further supported 
by more recent work which demonstrated that when the Linda Problem is framed as a query search for a computer database, where the description is framed as a set of parameters (e.g., age $=31$, college major $=$ philosophy) conjunction errors are yet again reduced (Maguire et al., 2018).

Table 4.1 summarizes key experimental manipulations and their relative incidence of conjunctive errors. Each study used the original construction of the Linda Problem and such related items (referred to as Probability judgment), unless otherwise specified.

Table 4.1: Key studies on the conjunction error

\begin{tabular}{|c|c|}
\hline Study & Percentage of conjunction errors committed (\%) \\
\hline \multicolumn{2}{|l|}{ Tversky and Kahneman $(\overline{1983})$} \\
\hline Probability Judgment & 87 \\
\hline Willingness-to-bet & 65 (received honoraria) \& 62 (hypothetical sum) \\
\hline \multicolumn{2}{|l|}{ Wells (1985) } \\
\hline Probability Judgment & 72 \\
\hline Two representative conjuncts & 24 \\
\hline Two unrepresentative conjuncts & 7 \\
\hline \multicolumn{2}{|l|}{ Fiedler (1988) } \\
\hline Probabilty Judgment & 73 \\
\hline Frequency Format & 23 \\
\hline \multicolumn{2}{|l|}{ Dulany and Hilton (1991) } \\
\hline Probability Judgment & 52 \\
\hline Author's Conjunction Error Criterion & 26 \\
\hline \multicolumn{2}{|l|}{ Politzer and Noveck (1991) } \\
\hline Probability Judgment & 77 \\
\hline Explicit Entailment Relationship & 41 \\
\hline Implicit Entailment Relationship & 29 \\
\hline \multicolumn{2}{|l|}{ Hertwig and Gigerenzer (1999) } \\
\hline Probability Judgment & 85 \\
\hline Probability Judgment after Typicality Judgment & 43 \\
\hline Tentori et al. (2004) & $\mathrm{X}, \mathrm{X}$-and-Y, X-and-not-Y \\
\hline Probability Judgment & 62 \\
\hline Frequency Format & 54 \\
\hline
\end{tabular}




\subsection{Criticisms and alternative views}

Despite the overall appeal of the representativeness hypothesis, it has been met with various criticisms. Broadly speaking, the representativeness hypothesis has been criticized for being too vague in the requisite conditions for it to occur. Particularly, there are some circumstances in which the conjunction error is robust, and other situations where individuals reason in a way consistent with probability and logic (Nisbett et al., 1983; Moro, 2009; Tentori et al., 2013). There are three prominent criticisms of the representative heuristic as presented in the Linda Problem: interpretations of probability (Gigerenzer, 1994; Hertwig and Gigerenzer, 1999), the polysemous nature of AND in natural language (Partee and Rooth, 1983; Hertwig et al., 2008; Mellers et al., 2001) and the pragmatic considerations of implicature availability (Politzer and Noveck, 1991; Adler, 1984; Tentori et al., 2004). This chapter will focus on the third criticism.

Individuals who commit the conjunction error are assumed to be observing Grice's Cooperative Principle and its subsequent maxims, further specified in section 2.2 (Grice, 1975, 1989). This assumption is consequential for how individuals respond to the conjunction problem based on Grice's maxims of Quantity and Relevance, which state that conversational participants should be maximally informative and relevant in their contributions.

Adler (1984) reduces the Quantity and Relevance maxims to what he coins as selective relevance, such that, for conjunction problems and other such contributions, participants expect that the information given in conjunction problems is true for one alternative and by consequence should not be true for another or potentially all of the other alternatives. The choice between "bank teller" and "bank teller and feminist" violates this expectation, as it is an odd comparison between a set and its subset (Dulany and Hilton, 1991; Politzer and Noveck, 1991). Adler argues that in conjunction problems, an answer that is true for more members of a set is less satisfying than an answer that applies to less members. "Bank teller" would be less discriminatory based on the given description of Linda and as a result less informative, especially in comparison to the latter. Assuming an individual answering the Linda Problem is obeying these maxims, they ought to choose an answer in a way that is most informative (e.g., Linda is a bank teller and feminist; Adler, 1984). Using a similar conjunction error problem, Mosconi and Macchi (2001, Exp. 1) demonstrate that when individuals were asked to judge the validity of the alternative that is statistically correct (e.g., Linda is a bank teller), they deemed the correct answer pragmatically inappropriate. Specifically, they either thought it was either false or reticent (only partially informative). 
Further to this effect, others argue that individuals reconcile the triviality of a comparison between a set and its subset by generating an implicature. In the context of the conjunction problem, the question is explicitly stated: "Which of the following statements is the most probable?". However, the interpretation of this question (the Question Under Discussion) is variable, based on the understanding of probability and other lexical items. Under pragmatic constraints, it is argued that individuals generate an implicature, where, both alternatives are on the same scale of informativeness (Adler, 1984; Politzer and Noveck, 1991; Dulany and Hilton, 1991):

\section{Linda is a bank teller (and not feminist).} Linda is a bank teller and a feminist.

Using this inference, choosing the answer bank teller and feminist as more likely does not violate any rules of probability. Dulany and Hilton (1991) note that this implicature bank teller and not feminist, referred to as the K-implicature is one of two possible implicatures, the other being bank teller, and she may or may not be a feminist or the so-called P-implicature. The K-Implicature is a scalar implicature, such that it maximizes the quantity of information described. The K-Implicature strengthens the basic meaning bank teller by virtue of the context, especially in comparison to the conjunction bank teller and feminist. The P-Implicature is the ignorance implicature, where it is inferred that since the speaker only asserted that Linda is a bank teller, that they are not opinionated about whether Linda is or is not a bank teller.

There have been many empirical attempts to block any resultant implicatures, yielding conflicting results (see Hertwig and Gigerenzer, 1999; Moro, 2009 for more detailed reviews). Summarizing some key experiments, in one of their earliest studies, instead of the alternative "Linda is a bank teller" Tversky and Kahneman (Tversky and Kahneman, 1983, p. 299) used "Linda is a bank teller whether or not she is in the feminist movement" to make the set of bank tellers inclusive to those who are also feminists more evident. This resulted in a reduction in the number of conjunction errors. Politzer and Noveck (1991, p. 90) similarly found a reduction in the conjunction error when the logically entailed implicature was separated from the basic meaning as in (33):

-Roland took an exam.

-Roland failed an exam.

-Roland passed an exam. 
Conversely, Agnoli and Krantz (1989) compared a standard conjunction problem, an explicit implicature version (bank teller and not a feminist) and a version with a blocked implicature version (bank teller and may or may not be a feminist). They predicted that there should be less conjunction errors when the implicature was blocked, yet they did not find a significant difference. More specifically, Tentori et al. (2004) found that conjunction error persists even when including alternatives that block the implicature or make the implicature explicit. This is particularly surprising because it was found using items phrased in a frequency format, which has been demonstrated to reduce the conjunction error. Tentori et al. (2004) findings were replicated by Wedell and Moro (2008) using the same experimental items.

Dulany and Hilton (1991) scrutinized the criterion for which researchers should classify choosing "Linda is a bank teller and feminist" as constituting a conjunction error. After participants completed the standard Linda Problem, the authors asked them how they interpreted "Linda is a bank teller", specifically (i) is not a feminist, (ii) is probably a feminist, (iii) probably not a feminist or (iv) whether she is feminist or not. They only considered those who committed the conjunction error and chose (iv). They determined that this was the appropriate criterion because those who interpret bank teller as (4) are verifiably comparing the set of bank tellers to the subset of bank tellers and feminist. Using this metric, the number of conjunction errors committed was significantly reduced (Dulany and Hilton, 1991; Hertwig and Gigerenzer, 1999).

All the findings summarized here describe the potential inferences available to a listener when one event is compared to a conjunction. This prompts related questions: does the conjunction error persist when the conjunction is compared to a disjunction? What are the available inferences when a conjunction is compared to a disjunction (i.e., bank teller or feminist)? This is of interest because disjunctions are entailed by the conjunction in a similar fashion to how the set is entailed the subset in the original construction. Specifically, it is necessarily true that Linda is a bank teller or a feminist, if she is a bank teller and a feminist. The crucial difference is that disjunctions eliminate the confound present in the original construction of the Linda Problem, where only one of the propositions (bank teller) as a set is compared to the subset of both propositions (bank teller and feminist).

In addition, plain disjunctions (this or that) are ambiguous in natural language between an inclusive (this or that or both) or exclusive (this or that but not both) interpretation. Scalar implicatures can resolve this ambiguity by denying the possibility of both events being true, resulting in its exclusive interpretation. Generally speaking, exclusive disjunctions are more informative, as they reduce the number of possible alternatives that 
could answer the Question Under Discussion compared to inclusive disjunctions and are thus preferred. However, in this scenario an inclusive interpretation (e.g., Linda is a bank teller or a feminist or both) would be preferable because it is more statistically likely. An inclusive disjunction allows for any of the possibilities to be true, especially in comparison to an exclusive disjunction which only allows one of the two propositions to be true, without asserting which. Thus, it would be of interest to determine the types of inferences that are preferable for a listener to make use of while judging the relative likelihoods of the sentences. The current study examined these circumstances.

\subsection{Experiment 1}

This study examined the effect of the representativeness heuristic relative to the influence of informativeness. Importantly, informativeness in the conjunction problem can be described as it relates to entailment (echoed in Adler's selective relevance), where if A entails B, A is less probable than B. Where if A entails B, for every instance of A, B is necessarily true. In the Linda example, "Linda is a bank teller and feminist" entails that "Linda is a bank teller". The converse is not true, in that, B can be true in instances where A is not (e.g., bank tellers who are not feminists). Thus B (bank tellers) is more probable than A (bank tellers and feminists). The same pattern emerges for inclusive disjunction: the set of bank tellers, feminists and feminist bank tellers are more probable than the set of bank tellers and feminists. Interestingly, the exclusive disjunction (e.g., bank teller or feminist and not both) breaks the entailment relationship that is present in the sentence "Linda is bank teller or feminist or both". Crucially, in this case, no rules of probability or set theory can determine which outcome is more likely between one of the two sets of non-feminist bank tellers or feminists non-bank tellers, respectively and the set of bank tellers and feminists.

To clarify the availability of the implicatures, the study aimed to determine if individuals would still prefer the conjunctive answer when presented with either plain disjunctions (which are ambiguous between an inclusive and exclusive interpretation) and or "or both" disjunctions (those with cancelled implicatures that invited an inclusive disjunction). 


\subsubsection{Design and Materials}

Participants responded to 10 items from three possible experimental conditions, as illustrated in Table 4.2 Items were counterbalanced using a Latin square method to ensure that each condition was adequately represented in the data. A willingness to bet paradigm was used as an alternative to asking for a probability judgment in order to avoid any possible misinterpretations of the term "probability"1 The full set of experimental items can be found in Appendix B.

Table 4.2: Sample item for original construction and disjunctive sentences of the Linda problem

Linda is 31 years old, single, outspoken and very bright. She majored in philosophy.

As a student, she was deeply concerned with issues of discrimination and social justice, and also participated in anti-nuclear demonstrations.

With the aim of getting $\$ 10$ to a local children's charity, which of the following do you think is most likely to be true?

\section{Original Construction}

Linda is a bank teller $(p)$.

Linda is a bank teller and a feminist ( $p$ and $q$ ).

Linda is a TV salesman.

Linda is a farmer.

\section{Plain Disjunction}

Linda is a bank teller or a feminist ( $p$ or $q$ ).

Linda is a bank teller and a feminist ( $p$ and $q$ ).

Linda is a TV salesman.

Linda is a farmer.

\section{Or-both Disjunction}

Linda is a bank teller or a feminist or both ( $p$ or $q$ or both).

Linda is a bank teller and a feminist $(p$ and $q)$.

Linda is a TV salesman.

Linda is a farmer.

\subsubsection{Predictions}

Condition 1. In condition 1 , when participants adopt the basic meaning (no exhaustified), $p$ and $q$ should be judged as less probable (albeit being more informative) than $p$ because the conjunction entails its con-

\footnotetext{
${ }^{1}$ This is based on the observation that participants were more likely to evaluate the Linda problem in terms of statistical probability when they were asked "Which of the two options are you more willing to bet on?". The rationale for this being that a monetary incentive promotes the more probable outcome in a statistical sense (i.e., what outcome would maximize their chances of getting a reward; Tversky and Kahneman 1983).
} 
juncts. If participants exhaustify the meaning of $p \Rightarrow p$ and not $q$ (e.g., bank teller and not feminist), the entailment relationship is broken, and neither answer is more probable than the other without any contextual strengthening. Given the description of Linda, this should bias individuals towards choosing bank teller and feminist.

Condition 2. When participants adopt the basic meaning (non-exhaustified) in condition $2, p$ or $q \Rightarrow p$ or $q$ or both, $p$ and $q$ entails $p$ or $q$ or both and $p$ and $q$ should thus be judged as less probable. If participants exhaustify the meaning of $p$ or $q$ to $p$ or $q$ and not both, the entailment is once again broken, the relative probabilities will be at the discretion of the participant. Therefore, one has to determine if one of the two options $p$ and not $q$ and $q$ and not $p$ without knowing which (equivalent to an exclusive disjunction), is more probable than both $p$ and $q$. Additionally, there is no information from the context that can help determine which outcome is most likely (i.e., nothing from the context that absolutely refutes that she is a bank teller).

Condition 3. Condition 3 does not allow for any strengthening, and similarly to the basic interpretation for condition 2, "Linda is a bank teller and feminist" entails that "Linda is a bank teller or feminist or both" and "Linda is a bank teller and feminist" should be deemed less probable.

Table 4.3: Predicted outcomes for choices in each condition based on exhaustification

\begin{tabular}{ccc}
\hline Condition 1 & $\boldsymbol{p}$ & $\boldsymbol{p}$ and $\boldsymbol{q}$ \\
\hline Exhaustification & & $\checkmark$ \\
Non-exhaustification & $\checkmark$ & \\
\hline Condition 2 & $\boldsymbol{p}$ or $\boldsymbol{q}$ & $\boldsymbol{p}$ and $\boldsymbol{q}$ \\
\hline Exhaustification & $\checkmark$ & $\checkmark$ \\
Non-exhaustification & $\checkmark$ & \\
\hline Condition 3 & $\boldsymbol{p}$ or $\boldsymbol{q}$ or both & $\boldsymbol{p}$ and $\boldsymbol{q}$ \\
\hline Non-exhaustification & $\checkmark$ & \\
\hline
\end{tabular}

Table 4.3 summarizes the predicted inferences in each condition. Taking stock, there is an ambiguity in conditions 1 and 2 depending on how an individual interprets the problem and the given alternatives and how they judge the associated probabilities with each answer. Based on the design of the conjunction error, the number of choices for the conjunction $p$ and $q$ (bank teller and feminist) can be expected to decrease with addition of weaker scalar terms in the relative comparisons. 


\subsubsection{Participants}

Two hundred and eleven participants completed the experiment as volunteers from a community sample or from the Carleton University undergraduate research pool for partial course credit $(0.25 \%)$ in an introductory Cognitive Science course. Volunteers received an invitation to the study shared via social media and did not receive any compensation for their participation. The study was approved by the Carleton University Research Ethics Board. Thirty-one participants reported that they were already familiar with the conjunction error and were removed from subsequent analysis for a total of 180 participants. Response choices and response time data were collected. No additional information (e.g., age, gender and other demographics) were collected from the participants of the study.

\subsubsection{Results}

Response times shorter than $15 \mathrm{~s}$ and longer than 200s were identified as extreme outliers using the boxplot method and removed from subsequent analysis. Responses chosen for the filler/distractor items (e.g., Linda is a farmer) were also removed from the analysis. Response times were analyzed using a linear mixed effects model using the "Imer" function from the "Ime4" package in R (Bates et al., 2015). The random effects structure included a random intercept for subjects. More complex random effects structures either overfit the data or failed to converge. "Condition" (with respect to Table 4.2) was the fixed effect. A likelihood ratio test between the full and reduced model (one that does not include "condition" as a factor) reveals no significant difference between conditions, $\chi^{2}(2)=0.93, p=0.63$.

Response choices were analyzed using a logistic mixed effects model using the "glmer" function from the "Ime4" package from R (Bates et al., 2015). Similarly to the response times, "condition" as a include in the model as a fixed effect, and the random effects structure used "subject" as a random intercept. A likelihood ratio test determine that there was a significant difference between conditions $\chi^{2}(2)=98.95, p<0.0001$, where participants were significantly more likely to make conjunction errors in condition (1.) compared to (2.), $\beta=3.44, z=7.34, p<0.0001$ and (3.) respectively, $\beta=3.27, z=7.21, p<0.0001$. There was no difference in conjunction errors committed between conditions (2.) and (3.), $\beta=-0.17, z=-0.54, p=0.85$. The p-values for the simple effects were adjusted for multiple comparisons using the Tukey method. Figure 4.1 presents these results below: 


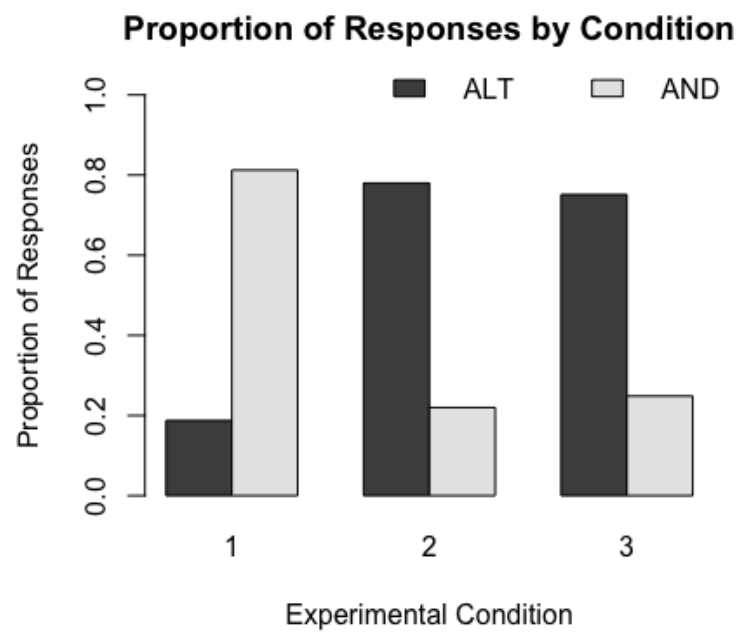

Figure 4.1: Proportions of response choices for the conjunctive sentence or the alternative in each condition. The alternative in condition 1 was one of the two propositions in the conjunction $p, p$ or $q$ in condition 2 and p or $q$ or both in condition 3 .

\subsubsection{Individual differences in response strategy}

I conducted an exploratory analysis of the dataset to further probe the possible inferences and response strategies that individuals could make use of in conditions $2 \& 3$. In order to examine this, participants were grouped based on their relative likelihood of choosing the alternative sentence in those conditions. Here, participants were categorized based on whether they preferred the answer $p$ and $q$ (e.g., bank teller and feminist) or if they preferred $p$ or $q$ in condition 2 or $p$ or $q$ or both in condition 3 . Mean participant response times shorter than $5 \mathrm{~s}$ were identified as outliers based on the spread of the data and were trimmed from the analysis, resulting in a total of 114 participants. Table 4.4 summarizes these findings.

Table 4.4: Number of participants by response choices in conditions 2 and 3.

\begin{tabular}{ccc}
\hline \multicolumn{3}{c}{ Condition 3 } \\
\hline Condition 2 & & \\
\hline$p$ and $q$ & 2 & and or $q$ or both \\
\hline$p$ or $q$ & 25 & 45 \\
\hline
\end{tabular}

Table 4.4 suggests that participants adopted distinct response strategies. To provide some further context into the available interpretations within the current design, recall from Section 2.2.1 that given the choice 
between two propositions, $p, q$, each proposition can be asserted or negated, summarized as: $\left\{p q, p q^{\prime}, p^{\prime} q\right.$, $\left.p^{\prime} q^{\prime}\right\}$. However, the experimental items used eliminates the option that both propositions are negated by always asserting that at least one of two propositions is true, where, bank teller and feminist is compared to bank teller, bank teller or feminist and, bank teller or feminist or both. The possible outcomes of the propositions are described in (34):

(i) bank teller and a feminist $(p q)$

(ii) feminist and not a bank teller $\left(p^{\prime} q\right)$

(iii) bank teller and not a feminist $\left(p q^{\prime}\right)$

Here, a conjunction $p$ and $q$ is consistent with (i), the exclusive $p$ or $q$, but not both disjunction is consistent with (ii) or (iii) respectively, and the inclusive disjunction $p$ or $q$ or both is consistent with all options (34-i) - (34-iii). Reiterating the predictions for this study, in condition 2, if participants do not exhaustify $p$ or $q$. Namely, they interpret this as $p$ or $q$ or both, they should choose $p$ or $q$ over $p$ and $q$. If they do exhaustify, they have a choice between (i) and one of (34-ii) or (34-iii), and this would be up to their judgment. In condition 3, participants should always choose $p$ or $q$ or both over $p$ and $q$ because it is commensurate with any of the choices (34-i) - (34-iii). However, as described in Table 4.4 this is not always the case. With this in mind, next I will outline the response strategies that correspond with the participant response choices described in Table 4.4

Starting with the 45 participants who chose $p$ and $q$ in condition 2 and $p$ or $q$ or both in condition 3 , it can be inferred that these individuals exhaustified the sentence in condition 2 as $p$ or $q$ but not both. This results in a comparison between (34-i) and one of (34-ii) or (34-iii), which is reducible to an exclusive disjunction. Probability theory has no predictions about which one of the two is more likely in this case, and these participants chose (34-i), which can be similarly expressed as $p$ and $q$, as more likely. In condition 3, the 45 participants choose $p$ or $q$ or both which is consistent with probability theory because it is inclusive to the all of the relevant possibilities. I conclude that they did exhaustify the sentence because if they did not exhaustify the meaning (interpreting $p$ or $q \Rightarrow p$ or $q$ or both in condition 2), they ought to choose $p$ or $q$ as the more probable answer, as it encapsulates all the possibilities associated with the asserted propositions. The 42 participants who chose $p$ or $q$ in condition 2 and $p$ or $q$ or both, did not exhaustify in condition 2 (interpreted $p$ or $q \Rightarrow p$ or $q$ or both) and made the same judgment in condition 3. 
For the 25 participants who chose $p$ or $q$ in condition 2 and $p$ and $q$ in condition 3 , I infer that these participants adopt a Question Under Discussion strategy, where they choose to exhaustify the meaning when available. Specifically, those in condition 2 are exhaustifying $p$ or $q$ but unlike the 45 participants who chose $p$ and $q$, they are judging that the exclusive disjunction is more likely. To further describe this, recall that the relevant comparison in condition 2 is between $p$ and $q$ and $p$ or $q$. The Question under Discussion in condition 2 can be described as a partition in (35). Note that in this case, truth and falsity is analogous to being a more probable answer and a less probable answer, respectively. Additionally, $p$ or $q$ is assumed to be an inclusive disjunction.

(i) $p$ and $q$ is true and $p$ or $q$ is true (Conjunction)

(ii) $p$ and $q$ is true and $p$ or $q$ is false. (Note that this is a contradiction because $p$ and $q$ entails $p$ or q)

(iii) $p$ and $q$ is false and $p$ or $q$ is true (Negating the conjunction $p$ and $q$ in the inclusive disjunction p or $q$ results in the exclusive disjunction)

(iv) $p$ and $q$ is false and $p$ or $q$ is false. (Note that this is an unlikely inference given the context and the possible answers in the experimental design).

Therefore (35-i) and (35-iii) are the only two viable options in condition 2. An inclusive interpretation of p or $q$ is compatible with both (35-i) where $p$ and $q$ is affirmed (conjunction) and (35-iii), where $p$ and $q$ is negated (exclusive disjunction). Adopting the view that some participants seek a complete answer to a question, therefore it can be said that those who chose $p$ or $q$ in condition 2 are exhaustifying the meaning. Again, the 45 and 2 participants from Table 4.4 who choose (35-i) in condition 2 exhaustify the meaning (picked a partition out of the cell). Here, the 25 participants similarly exhaustified but chose (35-iii) out of the partition described in (35). Then similarly in condition 3 , these 25 participants pick the conjunction out of the partition of possible inferences, because the disjunction $p$ or $q$ or both does not allow for a complete answer, as it is consistent with options (34-i) - (34-iii).

Given the small number of participants that chose $p$ and $q$ in both conditions 2 and 3 ( 2 participants), this may not reflect a true response strategy. An alternative explanation may be that again the 2 participants were assessing probabilities based on how suitable an answer is to the Question Under Discussion. Similarly, it could be the case that those participants found the conjunction the most likely answer in all conditions 
because it picks out a partition of the possibilities about the descriptions, whereas, the answers $p$ or $q$ and $p$ or $q$ or both do not. Table 4.5 summarizes the proposed response strategies.

Table 4.5: Number of participants in categorized by proposed response strategy. Note that the 2 participants that answered $p$ and $q$ in both conditions are not included because the effect may be negligible.

\begin{tabular}{ccc}
\hline & \multicolumn{2}{c}{ Condition 3 } \\
\hline Condition 2 & \\
\hline Exhaustification & Probability & Question Under Discussion \\
Non-exhaustification & 42 & 25 \\
\hline
\end{tabular}

\subsection{Experiment 2}

To further probe the rationale of individuals in each case of response strategy, I ran a follow-up study where participants were asked to rank the probabilities of each proposition as described of cells in partition of the two propositions $p, q$ from most probable (1) to least (4).

\subsubsection{Design and Materials}

Participants saw 10 items adapted from the previous experiment where the description of the person (e.g., Linda) remained the same. Items were presented in a uniquely randomized order to each participant. Choice response data and total experimental duration time were only data obtained from participants. Participants were asked to only use each number once in their rankings. Table 4.6 provides a sample of the items as they were presented to the participant.

\subsubsection{Participants}

Fifty participants were recruited using the same method as the previous experiment. This study was approved by the Carleton Research Ethics Board as an amendment to the main experiment. Three participants were removed from the analysis as they reported being familiar with some of the items presented. These items were presented alongside a similar follow-up experiment to the main experiment of Chapter 5 . As such, the items of one experiment served as fillers for the other. 
Table 4.6: Sample item for relative rankings of propositions in the Linda Problem.

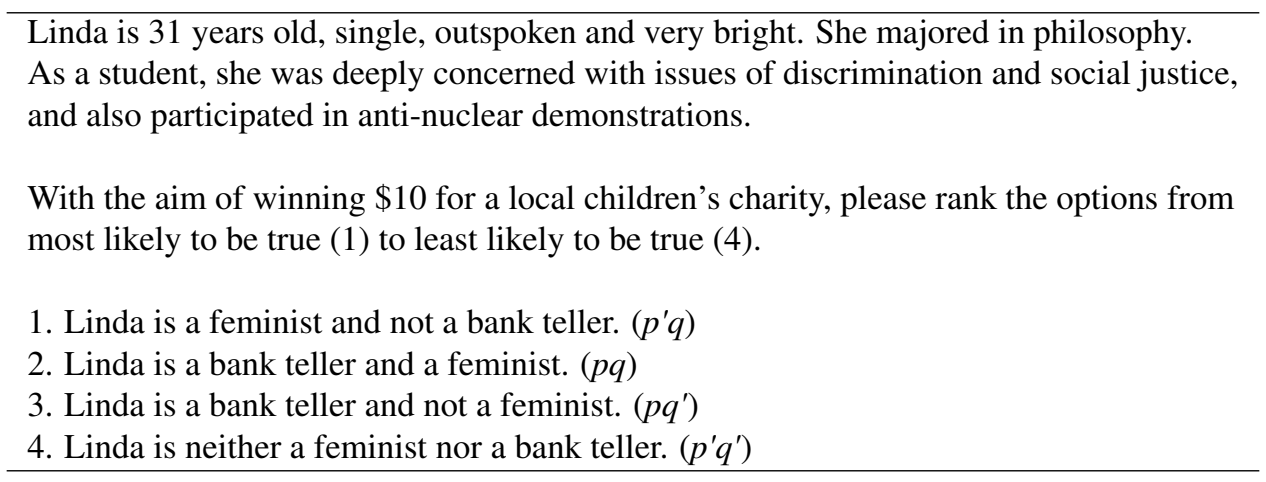

\subsubsection{Predictions}

The order in which the items are presented in Table 4.6 represent the predicted order of ranking. Particularly for the first two sentences, $p^{\prime} q$ will be rated as most likely, followed by $p q$. Then $p q^{\prime}$ and $p^{\prime} q^{\prime}$ may be equally as likely, as both negate the fact that Linda is a feminist, which was previously made salient by the description. Relative to those two cases, participants have to determine the likelihood of Linda being a bank teller without any prior knowledge given by the context.

\subsubsection{Results}

As some participants misinterpreted the task and responded in terms of percentages, responses less than 1 and greater than 4 were removed from the analysis. Total experiment duration times greater than $2000 \mathrm{~ms}$ were identified as outliers using the boxplot method and were removed from subsequent analysis. The total experiment duration times were intended simply to determine if participants were performing the task as intended and were not further analyzed. Table 4.7 presents the ranking for each type of sentence.

Table 4.7: Mean and median values for relative rankings of propositions. Note that smaller values correspond to a higher ranking.

\begin{tabular}{lcc}
\hline Sentence & Mean & Median \\
\hline$p^{\prime} q$ & 1.66 & 1 \\
$p q$ & 2.27 & 2 \\
$p q^{\prime}$ & 3.13 & 4 \\
$p^{\prime} q^{\prime}$ & 2.74 & 3 \\
\hline
\end{tabular}


These results confirm the predictions that the affirmation that Linda is a feminist were rated higher than its negation. Therefore, it can be said that the probability judgments were tied primarily to the likelihoods that Linda was a feminist. Interestingly, neither bank teller nor feminist was ranked higher than bank teller and not feminist. This is especially revealing for the 25 participants who presumably exhaustified and found $p$ or $q$ more likely than $p$ and $q$. It may be the case that these individuals chose the $p^{\prime} q$ cell of the partition and deemed this more probable than $p q$.

\subsection{Discussion}

The current study successfully replicated the conjunction error in its original form, as participants were more likely to choose the conjunction of the two propositions compared to one of the propositions alone. Additionally, the study significantly reduces the number of conjunction errors when conjunctive sentence is presented in comparison to both plain and inclusive disjunctive sentences. Looking further to individual subject behaviours revealed distinct response strategies between exhaustification and non-exhaustification. Namely, whether they would keep the basic meaning or exhaustify it.

The response strategies are also revealing of the possible epistemic states of the participants and how they can make use of these beliefs when judging the probabilities associated with each outcome. Specifically, it appears as though participants' beliefs are taking into account how useful the answer is to answering a Question Under Discussion, in that, a particular subgroup of the study's sample would adopt this strategy as a method of assessing probabilities, rather than choosing based on actual likelihoods. While this current study doesn't provide the level of granularity to say for certain when participants are exhaustifying their responses and the processes involved therein, it does suggest certain considerations that participants make in choosing their responses. In this experimental design, participants have to decide the likelihood of each proposition being true as they are presented (i.e., as a conjunction or a disjunction), particularly when the context is only representative of one of the combined descriptions. Here, implicature appears to be an influence on the associated probabilities of the descriptions, although this effect is difficult to dissociate from other inferences individuals make.

Generally, this study provides interesting results in terms of successfully reducing the conjunction error, while maintaining an entailment relationship. It also raises some relevant questions on an individual's 
intuitions about the component and combined probability of events under uncertainty. 


\section{Chapter 5}

\section{Hurford's Constraint and Natural Categories}

This chapter outlines entailment relationships between hierarchical categories and their perceived acceptability in discourse. A widely debated phenomenon first noted by Hurford (1974) stipulates that each disjunct in a disjunction is required to be semantically distinct, such that, one does not entail the other. This occurs to avoid redundancy and to maximize informativeness. Some disjunctions escape this requirement, such that, one disjunct can entail the other without violating any pragmatic expectations. In addition, conceptual categories appear to have an influence on whether the requirement applies or not. The current study aims to further address all these observations and their influence on understanding probabilities.

\subsection{Hurford's Constraint}

Hurford (1974 p. 410) articulates that a disjunction is interpreted as infelicitous if one of its disjuncts entails the other, as in (36) and contrasted by (37):

\#John is Californian or American.

John is American or Russian.

This observation has been generalized as Hurford's Constraint, where (36) is redundant because the informa- 
tion expressed by the disjunction, "John is either Calfornian or American", where the truth of each disjunct is unknown, can be equivalently expressed by the statement "John is American". Conversely, (37) does not violate Hurford's Constraint as being American and Russian do not entail each other. Hurford (1974, p. 410) also acknowledges that there are examples where this Constraint does not seem to be violated, as in (38):

Inmates are allowed to smoke or drink or both.

In its basic interpretation, the first disjunct (represented as a disjunction), "drink or smoke" entails the second "or both". Yet, Hurford argues that "smoke or drink" is interpreted exclusively, specifically that, inmates are allowed to do either one or the other thereby implicating that they are not allowed to do both ("smoke or drink" and not both). In this case, "or both" does not specifically entail the first disjunction, rather it explicitly reinforces the basic/inclusive interpretation of or. Conversely, violations to Hurford's Constraint cancel the implicature (in (36), John is Californian $\nRightarrow$ John is Californian and not American). Hurford uses the contrast in interpretations of (36) and (38) to demonstrate the ambiguity between inclusive and exclusive interpretations of or.

\subsubsection{Pragmatic Considerations}

Gazdar (1979, p. 81) argues that Hurford's Constraint can be obviated (violated without consequence) using any scalar term where a supposed entailment relationship can be broken:

a. Susie did some or all of her homework.

b. John has two or three kids.

In both examples of (39) one disjunct (all, three; the stronger disjunct) entails the other (some, two; the weaker disjunct). Under Gadzar's formulation, the examples in (39) are acceptable because some implicates not all (as opposed to some and possibly all) and two implicates only two (as opposed to at least two). This is in contrast to the Hurford disjunction in (36) where the weaker disjunct (American) cannot refute the stronger one (Californian). As a generalization, Gadzar notes that when disjuncts are scalar alternatives (with respect to Horn's (1972) scales) Hurford's Constraint does not apply as the entailment between disjuncts can be broken through a scalar implicature. Fox (2007) further describes the acceptability of Hurford's Constraint when comparing scalar terms and other lexical items through the notion of innocently excludable alternatives. 
Alternatives that are innoncently excludable can be denied without contradiction. Looking at some (39-a) with the basic interpretation some or possibly all, the scalar alternative all can be denied without contradicting the meaning of some. For (36) on the other hand, one cannot assert that John is California and deny that he is American without contradiction. Singh (2008) further claims that obviating Hurford's Constraint based on scalar alternatives is asymmetrical, where, Susie did some or all of her homework is only acceptable when the weaker disjunct is presented before the stronger one. Singh also states that Hurford's Constraint is applied incrementally and requires the disjuncts not to be mutually consistent.

Based on Gricean maxims of Relevance and Quantity, Simons (2001) illustrates two requirements for the felicity of Hurford's disjunctions: relevance and distinctiveness of alternatives. The relevance requirement is related to the maxim of Relevance, where the alternatives outlined by the disjunction need to be both relevant to the Question Under Discussion and as a result in some way need to be related to each other. This was similarly echoed by Grice (1989). Consider (40):

Either the computer needs repairs or the cake is in my refrigerator.

The disjunction in (40) is odd as there is no sensible relationship between the disjuncts. More generally said, it would be unclear what type of Question Under Discussion that the disjunction as a whole would satisfactorily address. The distinctiveness requirement indicates that while the alternatives in a disjunction need to be related, they also need to be distinct in such a way that each disjunct's contribution to the overall disjunction is informative. This requirement is paralleled by Singh's (2008) condition of mutual inconsistency. Hurford's Constraint demonstrates that oddness arises as a result of the redundancy between disjuncts. Simons notes that disjunctions that violate Hurford's Constraint are vacuous, in that, the disjunction as a whole and the one of the disjuncts express the same amount of information. Further to this point, Simons proposes that the disjunction as a whole must provide an answer to the Question Under Discussion that is different than the answer that can be obtained from either disjunctive alternative. For the example Susie ate cake or ice-cream, each disjunct would provide a unique answer to the question of what Susie ate, as well as the disjunction (it was one of the two, or possibly both).

Simons (2001 , p. 612) does also note that there are some exceptions to Hurford's Constraint outside of the scalar alternatives. Specifically those that are used for rhetorical effect as in (41), and what Simons describes as metalinguistic disjunction (citing Horn, 1985) as presented in (41) and (42): 
Either it'll rain or it'll pour.

John is from Paris or at least he is from France.

The acceptability of examples (41) and (42) is explained that they are not true disjunctions. (41) is a tautological statement and exclusively distinguishes between raining and pouring for emphasis. For (42) through the use of at least to qualify how Paris is entailed by France. Additionally, if "or" was removed from the statement (John is from Paris. At least he is from France) is does not change the meaning. Interestingly, these metalinguistic disjunctions are subject to the same asymmetry criterion as those that incorporate scalar alternatives (e.g., \#John is from France or at least he is from Paris).

Gazdar (1979) challenges Hurford's initial characterization of the Constraint in two ways: (i) cases that satisfy Hurford's Constraint do so by negating the second disjunct and (ii) counterexamples to Hurford's Constraint exist outside of disjunctive statements. Pertinent to (i) is that Gazdar disagrees with Hurford's conclusion that there are two distinct interpretations of or (i.e., inclusive/exclusive). Rather, Gadzar states that or only has an inclusive reading ("or is generally equivalent to or both") and exclusivity is obtained solely through implicature in appropriate contexts. He then specifies a criterion for which Hurford's Constraint is satisfied or violated, which is dependent on whether the entailing disjunct can be refuted or not by the context (whether the strengthened meaning is available). Looking again to (38) under this proposal, "smoke or drink" can negate the disjunct "or both", by strengthening the meaning of "smoke or drink". Explicitly this can be formulated as:

$$
\begin{aligned}
& \text { Inmates are allowed to smoke or drink or both. } \\
& \text { Inmates are allowed to smoke or drink (not both) or both. } \\
& p \vee q \vee p q \\
& (p \vee q) \neg(p q) \vee p q
\end{aligned}
$$

While this account does explain the apparent acceptability of (38), the pragmatic approach to obviating Hurford's Constraint has been met with criticism. Gazdar's (1979) approach focusses on what he coins clausal implicatures which presumes under Quantity, the negation of the scalar alternative functions in a similar manner to grammatical exhaustification, such that it rules out a scalar alternative (i.e., not both) based on strengthening the implicature. This presumption is problematic as the Quantity maxim only approximates the functionality of the grammatical exhaustification operator exh without any pragmatic motivation to do so. 
Specifically, all that the listener can definitively infer about the non-assertion of either disjunct in a disjunction is that the speaker is ignorant about the truth of either disjunct and their conjunction (or both). Simply using pragmatic principles, the listener cannot negate the conjunction (i.e., not both). Particularly, the presumption of an epistemic step does not resolve the redundancy associated with Hurford's disjunctions.

Schulz and Van Rooij (2006) propose a semi-pragmatic approach based on dynamic semantics which modifies the semantic approach of local embeddedness to the incorporate discourse referents. In this approach, the authors state that the disjuncts in the disjunction are treated as discourse referents, where attention is drawn to either disjunct (see Westera, $2018 \mathrm{~b}$ for a full characterization of clausal implicature and dynamic semantic approaches and criticisms). Additionally, Sauerland proposes that the obviation of Hurford's Constraint occurs as a repair strategy, specifically as an embedded speech act (see Sauerland, 2017 for a full characterization).

Most recently, Westera (2018b) proposes another pragmatic approach which departs from appeals to traditional maxims and implicatures, in what he denotes as Attentional pragmatics, where alternatives are identified as relevant based on how much attention they are given in context. Contrary to other pragmatic approaches, as well as the grammatical approach, Westera's view considers "or" as having a distinct interpretation to "or both". This differs from other views which generally presume that "or" in its literal interpretation is equivalent to "or both" and is subsequently exhaustified through implicature. A consequent of this is that Attentional pragmatics does not adopt Hurford's constraint and explains its conditions for felicity in other ways. Its response to Hurford's Constraint is founded on the assumption that "alternatives excluded in exhaustivity, whether pragmatic or by a grammatical operator $O$, must be relevant to the same Question Under Discussion (or goal or topic or some other model relevance)" (Westera, 2020, p. 3). This assumption is not contested by any of the other approaches mentioned but is of particular importance for Attentional pragmatics. Consider (44):

(44) a. My brother wants to go swimming.

b. My brother wants to go swimming or rockclimbing.

c. My brother wants to go swimming or rockclimbing or both.

Attentional pragmatics exhaustifies alternatives based on relevance and possibility. A speaker will draw attention to a set of alternatives that are presumed to be relevant and can possibly address a Question Un- 
der Discussion. In this view, (44-a) in comparison with the other statements predicts the implicature, not rockclimbing because if the speaker thought that rockclimbing was possible and relevant, they ought have mentioned this. In the same way, (44-b) predicts the not both implicature and (44-c) cancels it. Recall that under this approach "or" is not equivalent to "or both" and the implicature should always be available in (44-b).

In the context of Hurford's Constraint, Attentional pragmatics argues that the disjuncts are answering different Questions Under Discussion. Consider (45):

\#John is from Paris or France.

One general question that can be derived from this is "Where is John from?", where either disjunct on their own would be a sufficient answer. However, what Westera (2020) argues here is that this question as an interrogative statement does not have a direct one to one correspondence to the Question Under Discussion (as an interpretation of the interrogative statement) when the disjuncts Paris and France are presented together in a disjunction. Rather, the infelicity of the Hurford's disjunction arises from either disjunct addressing a different Question Under Discussion, namely “What country is John from?” and "What city is John from?". Scalar items (e.g., some, all) are alternatively argued to address the same Question Under Discussion by virtue of being on the same scale of informativeness.

\subsubsection{Grammatical Constraints}

The grammatical approach to Hurford Constraint is derived specifically from exhaustification, as outlined in Section 2.3. To briefly review grammatical exhausitification in this instance, the grammatical approach infers that scalar implicatures are generated as result of syntactic and semantic operations (i.e., the $O$ and $e x h$ operators, which approximate the meaning only in natural language) systematically applied to a sentence/subsentence structures. In contrast to the pragmatic approach, which operates at the level of speech acts and meaning in context, the exh operator can be applied within a sentence. This phenomenon is known as local embeddedness (Singh, 2008; Chierchia et al. 2012, 2008; Katzir and Singh, 2014). Recall that exh is marked by its optionality, where the sentence is first interpreted literally, then may or may not be re-parsed with the exh operator. Local embeddedness can resolve violations to Hurford's Constraint by applying the exh operator within the sentence. Using (38), repeated here as (46): 
Inmates are allowed to smoke or drink or both.

exh(Inmates are allowed to smoke or drink) or both.

Here, the exh is applied locally to the first disjunction and then globally to the entire sentence. The pragmatic approach, in its traditional Gricean characterization can only account for the global constraints which results in (47):

(Inmates are allowed to smoke or drink or both) not both.

(47) is evidently a violation of Hurford's Constraint. The pragmatic approach cannot account for the secondary implicature required to generate an acceptable interpretation of (47) in a way that is as parsimonious as local embeddness of the exh operator. Crucially, the grammatical view is contingent on Hurford's Constraint. More fundamentally, the grammatical view rests on the notion of redundancy and informativeness itself as a criterion of when the operator will apply, such that exh will apply to scalar alternatives that license the implicature, and consequently can break the entailment between disjuncts (Singh, 2008; Katzir and Singh 2014).

As previously mentioned, Singh (2008) denotes three features integral to the felicity of Hurford disjunctions, they are: asymmetrical, incremental and mutually inconsistent. Singh describes asymmetry in Hurford's Constraint as an order constraint on how local exhausitification applies. Using an example adapted from Chierchia et al. (2012, p. 21):

Jane completed the first or the second problem or she completed all of the problems.

Here, exh can be applied locally and globally in a similar manner to (46). However, if we were to reverse the order of the disjuncts, exhaustification alone cannot accommodate Hurford's Constraint:

\#Jane completed all of the problems or the first or the second problem.

Singh explains this observation by proposing that Hurford's Constraint is incremental, in that before exhaustification occurs, Hurford's Constraint is applied at each disjunct. As this occurs before the exh operator can be applied, the Hurford's Constraint must be verified using the basic meaning of the disjunct. If the basic meaning is not entailed by the second conjunct, Hurford's Constraint will dictate that a covert $O$ operator, with semantics similar to only, will be applied to exhaustify sentence acceptable: 
Jane completed all of the problems or only (the first or the second problem).

Lastly, Singh (2008, p.252) demonstrates that disjunctions will violate Hurford's Constraint if they are mutually consistent, such that there is some overlap between basic meanings despite the disjuncts not existing in an entailment relationship. Consider (51):

Susie ate some or not all of the cookies.

Here, some and not all convey the same information about the amount of cookies eaten. These features are further elaborated on by Katzir and Singh (2014) through their local redundancy principle, which is further articulated through the contextual equivalence (Ciardelli and Roelofsen, 2017). In very general terms, Katzir and Singh's (2014) local redundancy principle indicates that two disjuncts cannot be contextually equivalent or exist in the same set of possible worlds. Ciardelli and Roelofsen (2017) explain this using an example similar to (36), where the disjunction is only anomalous if the listener has the contextual knowledge that California is a state within America. This notion is similarly articulated in Simons's (2001) non-vacuity principle, which stipulates that the output of a logical operation must not be identical in informativeness to any of its inputs.

\subsection{Natural Categories}

Related to Singh's (2008) notion of mutually consistency are Horn's (1972) scales and degrees of informativeness. Recalling from Section 2.1 that Atlas and Levinson (1981) argue that scalar terms exist on an spectrum of informativeness from weak to strong (e.g., < some, all>) Matsumoto ( 1995) continues this line of reasoning by defining parameters in which lexical items in Horn scales can exist - either horizontally on their relative informativeness (e.g., some vs. all) or vertically on their degree of specificity (e.g., cold vs. $\left.-30^{\circ} \mathrm{C}\right)$. Therefore, Horn scales can be further particularized based on their level of elaboration, which is determined due to the demands of the context. The vertical degree of specificity is paralleled in psychological research on the hierarchy of semantic categories, between subordinate, basic and superordinate levels (e.g., spaniel, dog, mammal; Rosch, 1973; Rosch et al. 1976). Rosch et al. (1976) demonstrates that the cognitive system is organized in such a way that individuals respond to these hierarchies (see also Rosch, 1975; Lakoff, 1987; Collins and Quillian, 1969 and many more since). 
Crucially, Rosch et al. (1976) notes that the basic level is the most informative level of categorization in terms of explanatory value, as it selectively differentiates between the maximum number of instances that can belong to a category and those that do not. Matsumoto (1995) further elaborates as the basic category being the prototypical choice for a referent in most contexts, as it usually does not need to be further explained. Westera (2018b) adds to this line of reasoning by acknowledging that if a speaker were to use a more specific level of categorization, this would typically occur after first establishing the basic level of category of that instance (i.e., one should determine that it is a bird before asking if it is a macaw). However, the level of categorization is contextually dependent, where a more superordinate or subordinate level of the category may in fact be appropriate for the given conversation.

An example mentioned by Matsumoto $(1995$, p. 28) repeated here illustrates that mixing levels of categorization does not typically generate a scalar implicature.

(52) a. (A and B are talking about their neighbor Jane. Both knows that she has only one dog that it is a spaniel.)

A: What is Jane doing there?

B: She is walking her dog.

b. \#(B believes) Jane is not walking her spaniel.

Hierarchical terms such as $d o g$ and spaniel often do not generate an implicature from the entailed term. This agrees with Atlas and Levinson (1981) criteria of degree of lexicalization. To this end, Westera (2018b) proposes that these conceptual/categorical hierarchies influence the felicity of Hurford's Constraint. Specifically, Westera argues that examples such as Susie did some or all of her homework are acceptable because while they make up a Horn scale between <some, all>, it is a horizontal scale and as such, they both exist on the same hierarchical level as each other (they are both basic quantifiers). Numerals like John has two or three children similarly have numbers in the same vertical hierarchical category. Conversely, the distinct comparisons of such categories as Californian and American and Paris and France, are a mismatch of categories between cities/states and countries. Westera echoes the sentiment of Simons (2001) by stating that it is difficult to conceive of a Question Under Discussion that would be inclusive to a disjunction that mentions both the basic and superordinate levels of the same category due to its redundancy. One modification that resolves this conflict between hierarchical categories is shifting relevance through the use of more specifically 
and more generally:

John is Californian, or more generally, American.

John is American, or more specifically, Californian.

This, however, is similar to the use of at least described in Section 5.1.1, and is subject to the same criticisms, in that, it does not constitute a true disjunction.

That all being said, Potts and Levy (2015) examined corpus data and found that individuals do frequently violate Hurford's Constraint in conversation. They attributed it to two particular strategies: (i) resolving the lexical uncertainty attributed to a referent and (ii) communicating expertise/definitional information. For (i), they cite internet examples such as "Sometimes we buy furniture or chairs", where chairs is entailed by the category of furniture. Here, it seems as though the speaker is attempting to communicate the scalar implicature furniture other than chairs (Potts and Levy, 2015, p. 3). In this strategy, Potts and Levy indicate that individuals may simply conceptualize the two disjuncts as exclusive. Alternatively, Potts and Levy propose that the speaker may anticipate listener expectations under a Gricean framework, and assume that individuals will generate a scalar implicature anyways. The speaker preemptively makes the negated term explicit in the disjunct. They use the example "cheap or free", such that it is assumed that individuals interpret "cheap" as "cheap and not free", rather than "cheap and possibly free" (p. 4).

Interestingly for (ii), corpus examples such as “you may need angioplasty or surgery” and "wine lover or oenophile" are used to describe specificity or expertise, respectively (p. 1). Potts and Levy explain that in these cases, the Hurford's disjunctions distinguish between specific and general instances, as in "angioplasty or surgery", the implicature "angioplasty or surgery other than angioplasty" designates that the speaker believes that the listener requires some type of surgery, most likely an angioplasty. In the case of wine lover or oenophile (a synonymous term for wine lover), Potts and Levy explain that oenophile is explicated to distinguish from the casual fan of wine to those who are true connoisseurs (i.e., "wine lovers who are not oenophiles and oenophiles). Generally, Potts and Levy's (2015) study adds some nuance to the pragmatic considerations required to understand the felicity of Hurford's Constraint. 


\subsubsection{Disjunction error}

A related to phenomenon to Hurford's Constraint is the disjunction error as described in the psycholinguistic literature. Similar to the conjunction error described in Chapter 4, the disjunction error represents an error of extensional reasoning, where individuals misjudge the probability of a disjunct as more likely than the disjunction when given a context that biases the likelihood of the disjunct over the disjunction. In terms of statistical probability, the union of two events (represented by a disjunction) has a greater likelihood than any one event alone (disjuncts). Said differently, the likelihood of one of the two events, or both occurring is greater one of the events on its own. This effect has been prominently displayed in terms of conceptual hierarchies, in that, the disjunct is represented by a subset/subordinate category and the "disjunction" is represented by a basic level category (Bar-Hillel and Neter, 1993). An example of a disjunctive error is represented by the experimental item Bar-Hillel and Neter, 1993, p. 1122):

(54) Danielle is sensitive and introspective. In high school, she wrote poetry secretly. Did her military service as a teacher. Though beautiful, she has little social life, since she prefers to spend her time reading quietly at home rather than partying. What does she study?
a. Literature
b. Humanities
c. Physics
d. Natural sciences

The context prompts participants to choose (a), however (b) compared to (a) is more statistically probable, as it is inclusive to literature or other subdisciplines within humanities. Bar-Hillel and Neter (1993) attribute this effect to the repreesentativeness heuristic and finds on average that $64 \%$ of participants commit the disjunction error. Similarly to the implicature generation that occurs with the conjunction error, it stands to reason that individuals could be generating the implicature "humanities and not literature", especially given the pragmatically odd construction of (54). One issue of Bar-Hillel and Neter's (1993) methodology is that categories of literature and humanities can be contested, where some institutions may classify such disciplines in different categories. The authors additionally had items that compared the set of continents to the subset of countries and then asked participants "What country is the person from?", therefore biasing the answer to the subset. Additionally, all other such criticisms of the conjunction error can apply to the disjunction error 
(i.e., misinterpretations of the term probability and the ambiguous nature of or in natural language).

Carlson and Yates (1989) investigate the possibility that individuals take on an inclusive interpretation of the disjunction i.e., or both), through self-report and determined that the majority of individuals do not interpret the disjunctive sentence inclusively, where participants are generating a scalar (exclusivity) implicature in order to accommodate the comparison between the subordinate and basic level categories.

In general, research on the disjunction error is scarce, and even less so from a pragmatic standpoint. Therefore, the current research aims to first replicate the disjunction effect with novel stimuli.

\subsection{Experiment 1}

This research investigated the disjunction error from the perspective of Hurford's Constraint and principles governing its felicity. Specifically, it aimed to clarify the nature of the acceptability of Hurford's Constraint in the disjunction error using distinct category membership. Category membership was derived based on Rosch's (1973) notion of the category hierarchy. As a replication study of the disjunction error, it is expected that participants will choose the more specific category (John lives in New York) more frequently than the more general one (John lives in the United States).

Again, I adopt the position that entailment is related to informativity and is consequently reflected in probability judgments. Assuming that literature is a major within the discipline of humanities, (54) the subset literature entails the set humanities and should be thus less probable or equally as probable as the set. However, if participants re-interpret humanities the comparison between literature and humanities as humanities but not literature, this breaks the entailment relationship between the set and the subset, and then indivdiduals are free to judge which of the two literature and humanities and not literature is more likely.

\subsubsection{Participants}

Two hundred and eleven participants were recruited either as volunteers from a community sample or from the Carleton University undergraduate research pool (SONA) for partial course credit $(0.25 \%)$ in an introductory cognitive science course. Volunteers received an invitation to the study shared via social media and did not receive any compensation for their participation. A hundred and eighty participants were used in the 
analysis $^{1}$

\subsubsection{Design and Materials}

Ten experimental items used two propositions that exist in a entailment relationship among two filler propositions. The propositions were presented as alternative options to the question of interest, as an analogue to Hurford disjunctions (i.e., the choice between one option or the other option which is entailed by the first option). A sample of the items used in the study is provided in Table 5.1. I used a willingness to bet paradigm to reinforce statistical likelihoods and avoid issues related to misinterpreting the term "probability". Experimental items were presented with the conjunction error item from Chapter 4 (each investigation served as filler items for the other). No additional information (e.g., age, gender and other demographics) were collected from the participants of the study. The full set of items can be found in Appendix C.

Table 5.1: Sample item for Experiment 1.

John is a powerful banker. He makes lots of money, he drives a Benz (when he's not being driven around in limousines), he travels a lot, and he has a penthouse suite in a fancy condo.

With the aim of winning $\$ 10$ for a local children's charity, which of the following do you think is most likely to be true?

a. John lives in New York.

b. John lives in the United States.

c. John lives in Poland.

d. John lives in Vancouver.

\subsection{Results}

Response times less than 20s and greater than 200s were identified as outliers and trimmed from further analysis. Response counts were analyzed using a exact binomial test, using the "binom.test" function from the "stats" package in R (R Core Team, 2019). A binomial test was used as opposed to other null hypothesis tests (e.g., ANOVA, mixed effects models), as there was only one experimental condition. The binomial test determines if participants are choosing either option more often than chance. Within the parameters of the binomial test, one set of response is chosen as "successes" and the other is chosen as "failures". The

\footnotetext{
${ }^{1}$ As the Hurford's Constraint items were presented in the same study as the conjunction error, the subjects who reported being familiar with the conjunction error were also removed from this analysis as a precaution that those participants may also be aware of disjunctive errors/be able to extensionally apply statistical reasoning to those cases based on knowledge of the conjunction error.
} 
proportions for each response are compared to the total number of responses. The proportion of successes are compared to the success rate at chance. Practically, this was done by identifying disjunctive errors as successes relative to the total number of trials completed. Significance values were determined using a probability threshold of 0.5 (chance level for choosing the binary response variable) and a confidence interval of 95\%. The analysis determined that participants are significantly more likely to break the entailment between the set and its subset and thus violate Hurford's Constraint $(p<0.016$, 95\% C.I.[0.51, 0.58]). Similarly to Chapter 4, this result demonstrates that contextual bias influences informativity between a set and its subset, as one disjunct that entails another, by breaking the entailment relationship.

\section{Relative Number of Violations of Hurford's Constraint}

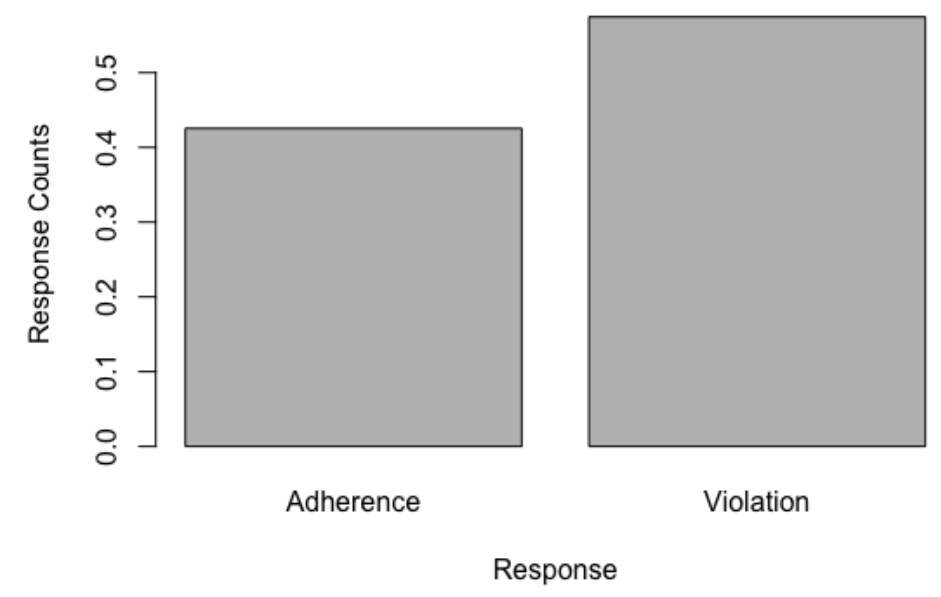

Figure 5.1: Proportion of responses for violations to Hurford's Constraint

\subsection{Experiment 2}

A follow-up to Experiment 1 was conducted to further dissociate the acceptability of Hurford's Constraint. The aim in the follow-up was to determine whether violations to Hurford's Constraint persisted when the scope of alternatives was increased. Additionally, this follow-up aimed to identify the types of inferences that are available in these particular contexts. 


\subsubsection{Design \& Materials}

The same ten items used for Experiment 1 were adapted in the current study. Participants were shown the same context as in Table 5.1, but were instead shown alternatives that were Hurford's disjunctions compared to disjunctions that did not violate Hurford's Constraint. Fifty participants were asked to rank the options as most (1) to least (4). As these materials were presented alongside the follow-up study in the previous chapter, the same participants excluded in that study were excluded here. Table 5.2 provides a sample item used in the experiment:

Table 5.2: Sample item for Experiment 2.

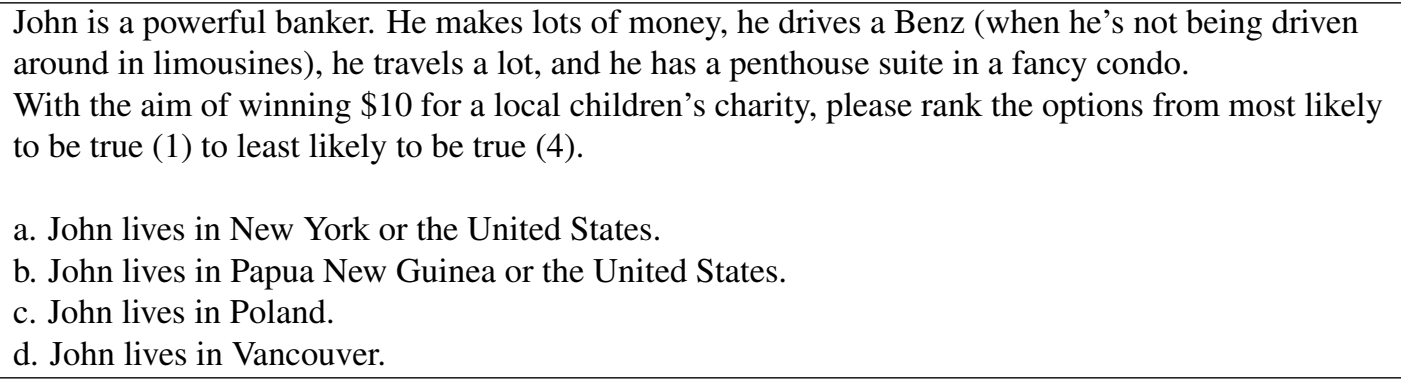

\subsubsection{Results}

Responses less than 1 and greater than 4 were removed from the analysis, as there were participants who misinterpreted the task and responded in terms of percentages. Total experiment duration times greater than 2000ms were identified as outliers using the boxplot method and were removed from subsequent analysis. The total experiment duration times were intended simply to determine if participants were performing the task as intended and were not further analyzed. Response choices and response times were the only data that was collected from participants.

Table 5.3: Mean and median values for relative rankings of disjunctions and filler items. Note that smaller values correspond to a higher probability ranking.

\begin{tabular}{lcc}
\hline Sentence & Mean & Median \\
\hline HC disjunction & 1.66 & 1 \\
Plain disjunction & 2.15 & 2 \\
Filler items & 3.00 & 3 \\
\hline
\end{tabular}

Based on a principle of mutual exclusivity, the plain disjunction should not be interpreted as inclusively. 
For example, using the items presented in Table 5.2, in (b) participants should interpret this as John lives in either Papua New Guinea or the United State and not both ${ }^{2}$. In this situation, they have a choice to choose between (b) which asserts that John lives in either Papua New Guinea or the United States, without knowing which, or (a) which asserts that John lives in United States (or New York, which is ultimately entailed by the United States). Here, the Hurford's disjunction provides a more informative (less probable) answer in comparison to the plain disjunction, whether it is interpreted as inclusively or exclusively. Specifically, whether participants interpret (a) to mean, New York or the United States but not New York, or if they interpret (a) to mean New York or the United States or both, they should arrive at the same answer that a speaker is asserting that John lives somewhere in the United States.

\subsection{Discussion}

Experiments 1 and 2 demonstrate how violations to Hurford's Constraint occur in situations where informativeness is not dictated by what logically entails another. Similar to the experiments in Chapter 4 generally, Experiments 1 and 2 provide support to the claim that contextual information can break the entailment between a set and its subset. Further analyses suggest that, while Hurford's disjunctions are generally preferred, the saliency of the category membership slightly influences the relative rankings of the disjunctions, were distinct category membership à la Rosch's (1973) natural categories. This effect is presumed to be the result of the availability of an inclusive/exclusive interpretation.

Recall that the acceptability of Hurford's Constraint is dependent on extent to which the disjuncts in a disjunction are distinct from one another. In regular conversations, Hurford's disjunctions are so closely related that one disjunct is made redundant by other. In these situations examined by the two experiments, participants are given underinformative and irrelevant information and in spite of this are asked to make a probability judgment. Additionally, under Attentional pragmatics, participants may be responding to more than one Question Under Discussion. This is the result of category membership, which can arguably shift relevance between disjuncts, yielding two Questions Under Discussions to be addressed. Under this view, it may be the case that in either experiment, the participants have to make two choices, an interpretation between which Question Under Discussion to address and which of the alternatives presented in the question sufficiently addresses it. In Experiment 1, those who chose the stronger alternative (e.g., John lives in New

\footnotetext{
${ }^{2}$ Unless one interprets this to mean that John splits his time between both countries.
} 
York City) may be responding to the Question Under Discussion requiring the higher level of specificity. On the other hand, those who chose the weaker alternative (e.g., John lives in America) may be responding to the Question Under Discussion that is most informative. In Experiment 2, the findings are less clear, as a Hurford's disjunction was being compared a plain disjunction. In Westera's (2020) view, Hurford's disjunction presented two Questions Under Discussion (where one is more informative than the other), while the plain disjunction presumably only offers one Question Under Discussion. Under a specificity interpretation, disjunctions with disjuncts that are non-entailed are more informative, where each answer can conceivably answer one or several Questions Under Discussion.

The current study is limited in the generalizability of the experiment to the theories on Hurford's constraint, specifically between Attentional pragmatics and grammatical exhaustification. Particularly, it does not straightforwardly dissociate between either frameworks. One way to further investigate if Attentional pragmatics is a valid characterization how individuals judge the felicity of Hurford's constraint would be to explicate the possible Questions Under Discussion. For example, when given the disjunction John is from Paris or France to choose between the disjuncts Paris or France. Future studies should aim to determine the resultant effects from this design. 


\section{Chapter 6}

\section{Conclusion}

To conclude, in this thesis I have examined the behaviour of scalar implicature as it relates to answerhood in three contexts. The aim was to characterize the amount and ways in which information is conveyed can influence the generation of scalar implicatures. Chapter 3 determined that scalar implicatures are available when Quantity is not required in conversational contexts. Chapter 4 determined that scalar implicatures can break the entailment relationships present in between conjunctions and conjuncts, as well as between conjunctions and disjunctions. Additionally, distinct individual differences in response strategies emerged. Chapter 5 similarly determined that the relationship between Hurford's disjuncts can be broken when given a context that favours one of the disjuncts. Moreover, the distinctiveness of the conceptual hierarchies between plain and Hurford's disjunctions influenced their probability rankings.

Generally, I used the concept of a Question Under Discussion to describe the conversational goals that are arguably shared between interlocutors, as well as a basis for generating scalar implicatures from questions asked. The present studies demonstrate that while participants are addressing a Question Under Discussion in some way or another, it may not be interpreted in the way that is intended by the speaker. The possible status of the relevant alternatives can be successfully described under the format of the Question Under Discussion as a partition of logical space. This approach is useful in characterizing the inferences available to individuals based on their implicature preferences. Notably, individuals who exhaustify, aim to identify a particular cell within the partition of the Question Under Discussion. The question format of the studies constrained the permissible answers to the Question Under Discussion in particular ways. These studies also demonstrate 
those who do not exhaustify and retain the basic meanings also have inferences that are explainable similarly explainable as partitions derivable from a set of propositions.

The longstanding debate between the division of semantic and pragmatic labour in generating scalar implicatures was also discussed as they related to implicatures in the absence of Quantity maxims and with respect to Hurford's Constraint. One limitation of the studies described is that the theoretical approaches used to empirically test the phenomena presented here were described in very broad distinctions between the overarching schools of thought. As mentioned throughout, there are various offshoots associated with these views, especially within the pragmatic view. Therefore, the findings, particularly in Chapter 3, may be weakened by certain resolutions proposed by recent pragmatic theories within the overall pragmatic view.

The main methodological limitation of the experimental design was the use of an offline response choice task. This paradigm is well suited for the determination of linguistic intuitions, but it is not very revealing to the processes involved in making a certain probability judgment, particularly based on semantic and pragmatic theories of scalar implicature. In this manner, it is difficult to attribute the results causally to one theory over another. Future work should employ behavioural techniques, such as eye-tracking and neuroimaging in order to obtain online data on scalar implicature generation. Despite these findings being rather preliminary, the present research points to several directions for future studies to determine the conversational expectations that are required when the listener does have all of the relevant information, the effect on scalar implicatures and its subsequent influence on constraining the alternatives available in given Question Under Discussion. 


\section{Appendices}

\section{Appendix A: Experimental Stimuli for Chapter 3}

\section{Instructions}

Suppose you're on a game show where you have to choose an item from a set of options. Some of the items are associated with a million dollars, and the reset are associated with no money. You do not know which items are associated with money and which are not. The game show host does know, but they cannot explicitly tell you this information. However, at various points in the game, the host can give you hints. If you choose an item that has money associated with it, you will leave the game with a million dollars. If you choose an item that does not have money associated with it, you will leave the game with nothing. The game continues with a new contestant until all of the items in the set that are associated with money are chosen.

\section{Disjunctions}

1. Your task is to choose a numbered box. There are 100 numbered boxes in total and 5 of them contain a million dollar prize. The host tells the first contestant that there is money in box 20 or box $25 / \mathbf{b o x} 20$ or box 25 or both. This contestant picks box 20 and finds a million dollars there/discovers that the box is empty. Imagine you are the next contestant in this game. The host does not give you any hints. Which action are you most likely to take?
a.) Choose box 25 .
b.) Choose another box.
Variant of the boxes example.

2. Your task is to choose a numbered box. There are 4 numbered boxes in total and 2 of them contain a million dollar prize. The host tells the first contestant that there is money in box 1 or box $2 /$ box 1 or box 2 or both. This contestant picks box 20 and finds a million dollars there/discovers that the box is empty. Imagine you are the next contestant in this game. The host does not give you any hints. Which action are you most likely to take?

a.) Choose box 2 . 
b.) Choose another box.

3. Your task is to choose a letter from the English Alphabet. There are 26 letters in total and 4 of them are associated with a million dollar prize. The host tells the first contestant that there is money associated with the letters "E" or "Q"/“E" or "Q" or both. This contestant picks letter "E" and wins a million dollars/does not win any money. Imagine you are the next contestant in this game. The host does not give you any new hints. Which action are you most likely to take?

a.) Choose the letter "Q".

b.) Choose another letter.

4. Your task is to choose a card from a deck of cards. There are 52 cards in total and 5 of them are associated with a million dollar prize. The host tells the first contestant that there is money associated with the Three of Hearts or Eight of Clubs/Three of Hearts or Eight of Clubs or both. This contestant picks the Three of Hearts and wins a million dollars/does not win any money. Imagine you are the next contestant in this game. The host does not give you any new hints. Which action are you most likely to take?

a.) Choose the Eight of Clubs.

b.) Choose another card.

5. Your task is to choose a side from a 6-sided die. Each side has a number of dots ranging from 1 to 6 . There are 3 sides associated with a million dollar prize. The host tells the first contestant that there is money associated with the 2-dot side or the 4-dot side/2-dot side or the 4-dot side or both. The contestant before you picks the 2-dot side and wins a million dollars/does not win any money. Imagine you are the next contestant in this game. The host does not give you any new hints. Which action are you most likely to take?

a.) Choose the 4-dot side.

b.) Choose another side. 


\section{Numerals}

1. Your task is to choose a numbered door. There are 8 numbered doors and 4 of them are associated with a million dollar prize. The host tells the first contestant that there is money associated with one/at least one door with a number less than 3 . The contestant before you picks Door 1 and wins a million dollars/does not win any money. Imagine you are the next contestant in this game. The host does not give you any new hints. Which action are you most likely to take?
a.) Choose Door 2.
b.) Choose another door.

2. Your task is to choose a billiards ball. Each ball is labeled with a number ranging from 1 to 15 . There are 5 billiard balls associated with a million dollar prize. The host tells the first contestant that there is money associated with one/at least one ball with a number greater that 13 . The contestant before you picks the 15-ball and wins a million dollars/does not win any money. Imagine you are the next contestant in this game. The host does not give you any new hints. Which action are you most likely to take?
a.) Choose the 14-ball.
b.) Choose another ball.

3. Your task is to choose a jersey number. Each jersey is labeled with a number ranging from 1 to 32 (with no exceptions). There are 6 jerseys associated with a million dollar prize. The host tells the first contestant that there is money associated with one/at least one jersey with a number less than 3 . The contestant before you picks jersey number 2 and wins a million dollars/does not win any money. Imagine you are the next contestant in this game. The host does not give you any new hints. Which actions are you most likely to take?
a.) Choose jersey number 1 .
b.) Choose another jersey.

4. Your task is to choose a number from a spinning wheel. The spinning wheel is divided in 10 equal parts and each part is labeled with a number (i.e., 1 to 10). There are 3 numbers associated with a million dollar prize. The host tells the first contestant that there is money associated with one/at least one number greater 
than 8 . The contestant before you picks number 9 and wins a million dollars/does not win any money. Imagine you are the next contestant in this game. The host does not give you any new hints. Which action are you most likely to take?

a.) Choose number 10 .

b.) Choose another number. 


\section{Appendix B: Experimental Stimuli for Chapter 4}

\section{Experiment 1}

\section{Instructions}

You will be presented with a series of descriptions of various people. You will then be asked to judge, given the description of the person, which of a set of new descriptions is most likely to be true about the person. You will not have enough information to know for sure, but your goal is to be right so you should pick the one that strikes you as most likely to be right. To encourage this, we ask you to imagine that for each correct choice you make $\$ 10$ will go to a local children's charity, and that no money is associated with incorrect choices.

1. Linda is 31 years old, single, outspoken and very bright. She majored in philosophy. As a student, she was deeply concerned with issues of discrimination and social justice, and also participated in anti-nuclear demonstrations. With the aim of winning $\$ 10$ for a local children's charity, which of the following do you think is most likely to be true? (Tversky and Kahneman, 1983)
a.) Linda is a bank teller.
a') Linda is bank teller or a feminist.
a”) Linda is a bank teller or a feminist, or both.
b.) Linda is a bank teller and a feminist.
c.) Linda is a TV salesman.
d.) Linda is a farmer.

2. Allen is very shy and withdrawn, invariably helpful, but with little interest in people or in the world of reality. A meek and tidy soul, he has a need for order and structure. With the aim of winning $\$ 10$ for a local children's charity, which of the following do you think is most likely to be true? (Tversky and Kahneman 1983)
a.) Allen enjoys parachuting.
a') Allen enjoys parachuting or is a librarian.
a") Allen enjoys parachuting or is a librarian, or both. 
b.) Allen enjoys parachuting and is a librarian.

c.) Allen practices karate.

d.) Allen is fluent in four languages.

3. Bill is a middle aged adult. He is intelligent, but unimaginative, compulsive, and generally lifeless. In school, he was strong in mathematics but weak in social studies and humanities. He finds comfort in the organization of numbers. With the aim of winning $\$ 10$ for a local children's charity, which of the following do you think is most likely to be true? (Tversky and Kahneman, 1983)
a.) Bill is a nomad.
a'.) Bill is a nomad or is an accountant.
a".) Bill is a nomad or is an accountant or both.
b.) Bill is a nomad and an accountant.
c.) Bill is an expert on espionage.
d.) Bill likes to travel.

4. Stefan is 54 years old. He cultivated a large interest in computers as a child and today he holds an engineering degree with a major in computer technology. With the aim of winning $\$ 10$ for a local children's charity, which of the following do you think is most likely to be true? (Pagin, 2019)
a.) Stefan is a candle enthusiast.
a') Stefan is a candle enthusiast or a computer programmer.
a") Stefan is a candle enthusiast or a computer programmer or both.
b.) Stefan is a candle enthusiast and a computer programmer.
c.) Stefan writes poetry in his spare time.
d.) Stefan is from Morocco.

5. Caroline goes to church every Sunday. She gets most of her information about religion from speaking with a priest. She has a figurine of St. Mary at home. When she went to Rome last year, she visited the Vatican. With the aim of winning $\$ 10$ for a local children's charity, which of the following do you think is most likely 
to be true?
a.) Caroline is a computer hacker.
a') Caroline is a computer hacker or is Catholic.
a") Caroline is a computer hacker or is Catholic or both.
b.) Caroline is a computer hacker and Catholic.
c.) Caroline lives in Texas.
d.) Caroline is a fan of heavy metal.

6. Mary was involved from very early childhood in sports activities. She was the fastest runner in her neighbourhood. In junior high school, she was by far the best of her class in throwing and catching a ball. In college, she decided to major in physical education. She particularly enjoys the social interaction of team sports. With the aim of winning $\$ 10$ for a local children's charity, which of the following do you think is most likely to be true? (Agnoli and Krantz, 1989)
a.) Mary is a pickpocket.
a'.) Mary is a pickpocket or plays in a softball league.
a”.) Mary is a pickpocket or plays in a softball league or both.
b.) Mary plays is a pickpocket and plays in a softball league.
c.) Mary is a colour scientist.
d.) Mary loves vintage cinema.

7. Cindy is the daughter of a very famous ballet dancer. As child, she took extensive dance and gymnastic classes and routinely won first place in national competitions. All of her teachers regarded her as very talented and told her she had a bright future as a dancer. Cindy is now 28 years old. With the aim of winning $\$ 10$ for a local children's charity, which of the following do you think is most likely to be true?
a.) Cindy is a volunteer firefighter.
a'.) Cindy is a volunteer firefighter or a dancer.
a".) Cindy is a volunteer firefighter or a dancer or both.
b.) Cindy is a volunteer firefighter and is a dancer.
c.) Cindy plays chess competitively. 
d.) Cindy rides a motorcycle.

8. Jason's favourite subject in school was English. As child, he would routinely write short stories in his notebook. In high school, he volunteered with the school newspaper. One year, his parents bought him a vintage typewriter for his birthday as a gift. His favourite authors are Kurt Vonnegut, Emily Bronte and Charles Dickens. With the aim of winning $\$ 10$ for a local children's charity, which of the following do you think is most likely to be true?
a.) Jason enjoys hot air balloon rides.
a'.) Jason enjoys hot air balloon rides or a writer.
a”.) Jason enjoys hot air balloon rides or a writer or both.
b.) Jason enjoys hot air balloon rides and is a writer.
c.) Jason is a chef.
d.) Jason plays the theremin.

9. Kay is a nurturing, compassionate and caring person. She is the first person that her friends will go to for medical advice. She always has common over the counter medication and a first aid kit on hand. With the aim of winning $\$ 10$ for a local children's charity, which of the following do you think is most likely to be true?
a.) Kay manufactures fireworks.
a'.) Kay manufactures fireworks or a nurse.
a".) Kay manufactures firework or a nurse or both.
b.) Kay manufactures fireworks and is a nurse.
c.) Kay works at a call-centre attendant.
d.) Kay is a mathematician.

10. Michael loves working with his hands, especially, if he's tinkering with something. Never one for highly theoretical subjects in school, one of his favourite hobbies is to take apart small electronics and put them back together to figure out how they work. With the aim of winning $\$ 10$ for a local children's charity, which of the 
following do you think is most likely to be true?
a.) Michael is a germaphobe.
a'.) Michael is a germaphobe or a nurse.
a".) Michael is a germaphobe or a nurse or both.
b.) Michael is a germaphobe and a mechanic.
c.) Michael is an astronaut.
d.) Michael is a philosopher.

\section{Experiment 2}

\section{Instructions}

You will be presented with a series of descriptions of various people. You will then be asked to rank, given the description of the person, which of a set of new descriptions is most likely (1) to least likely (4) to be true about the person. Please only use number (e.g., 2) once while making your rankings. You will not have enough information to know for sure, but your goal is to be right so you should pick the one that strikes you as most likely to be right. To encourage this, we ask you to imagine that for each correct choice you make $\$ 10$ will go to a local children's charity, and that no money is associated with incorrect choices.

1. Linda is 31 years old, single, outspoken and very bright. She majored in philosophy. As a student, she was deeply concerned with issues of discrimination and social justice, and also participated in anti-nuclear demonstrations. With the aim of winning $\$ 10$ for a local children's charity, which of the following do you think is most likely to be true? (Tversky and Kahneman, 1983)
a.) Linda is a bank teller and a feminist.
b.) Linda is bank teller and not a feminist.
c.) Linda is a feminist and not a bank teller.
d.) Linda is neither a feminist nor a bank teller.

2. Allen is very shy and withdrawn, invariably helpful, but with little interest in people or in the world of 
reality. A meek and tidy soul, he has a need for order and structure. With the aim of winning $\$ 10$ for a local children's charity, which of the following do you think is most likely to be true? (Tversky and Kahneman $1983)$
a.) Allen is parachutist and is a librarian.
b.) Allen is a parachutist and is not a librarian.
c.) Allen is a librarian and is not a parachutist.
d.) Allen is neither a parachutist nor a librarian.

3. Bill is a middle aged adult. He is intelligent, but unimaginative, compulsive, and generally lifeless. In school, he was strong in mathematics but weak in social studies and humanities. He finds comfort in the organization of numbers. With the aim of winning $\$ 10$ for a local children's charity, which of the following do you think is most likely to be true? (Tversky and Kahneman, 1983)
a.) Bill is a nomad and is an accountant.
b.) Bill is a nomad and is not an accountant.
c.) Bill is an accountant and not a nomad.
d.) Bill is neither an accountant nor a nomad.

4. Stefan is 54 years old. He cultivated a large interest in computers as a child and today he holds an engineering degree with a major in computer technology. With the aim of winning $\$ 10$ for a local children's charity, which of the following do you think is most likely to be true? (Pagin, 2019)
a) Stefan is a candle enthusiast and a computer programmer.
b.) Stefan is a candle enthusiast and is not a computer programmer.
c.) Stefan is a computer programmer and a candle enthusiast.
d.) Stefan is neither a candle enthusiast nor a computer programmer.

5. Caroline goes to church every Sunday. She gets most of her information about religion from speaking with a priest. She has a figurine of St. Mary at home. When she went to Rome last year, she visited the Vatican. With the aim of winning $\$ 10$ for a local children's charity, which of the following do you think is most likely 
to be true?

a.) Caroline is a computer hacker and is Catholic.

b.) Caroline is a computer hacker and is not Catholic.

c.) Caroline is Catholic and not a computer hacker.

d.) Caroline is neither a computer hacker nor Catholic.

6. Mary was involved from very early childhood in sports activities. She was the fastest runner in her neighbourhood. In junior high school, she was by far the best of her class in throwing and catching a ball. In college, she decided to major in physical education. She particularly enjoys the social interaction of team sports. With the aim of winning $\$ 10$ for a local children's charity, which of the following do you think is most likely to be true? (Agnoli and Krantz, 1989)

a.) Mary is a pickpocket and a softball player.

b.) Mary is a pickpocket and is not a softball player.

c.) Mary is a softball player and not a pickpocket.

d.) Mary is neither a pickpocket nor a softball player.

7. Cindy is the daughter of a very famous ballet dancer. As child, she took extensive dance and gymnastic classes and routinely won first place in national competitions. All of her teachers regarded her as very talented and told her she had a bright future as a dancer. Cindy is now 28 years old. With the aim of winning $\$ 10$ for a local children's charity, which of the following do you think is most likely to be true?

a.) Cindy is a volunteer firefighter and a dancer.

b.) Cindy is a volunteer firefighter and is not a dancer.

c.) Cindy is a dancer and is not a volunteer firefighter.

d.) Cindy is neither a volunteer firefighter nor a dancer.

8. Jason's favourite subject in school was English. As child, he would routinely write short stories in his notebook. In high school, he volunteered with the school newspaper. One year, his parents bought him a vintage typewriter for his birthday as a gift. His favourite authors are Kurt Vonnegut, Emily Bronte and Charles 
Dickens. With the aim of winning $\$ 10$ for a local children's charity, which of the following do you think is most likely to be true?

a.) Jason operates hot air balloons and a writer.

b.) Jason operates hot air balloons and is not a writer.

c.) Jason is a writer and does not operate hot air balloons.

d.) Jason is neither a writer nor does he operate hot hair balloons.

9. Kay is a nurturing, compassionate and caring person. She is the first person that her friends will go to for medical advice. She always has common over the counter medication and a first aid kit on hand. With the aim of winning $\$ 10$ for a local children's charity, which of the following do you think is most likely to be true? a.) Kay manufactures fireworks and is a nurse.

b.) Kay manufactures fireworks and is not a nurse.

c.) Kay is a nurse and does not manufacture fireworks.

d.) Kay is neither a nurse nor does she manufacture fireworks.

10. Michael loves working with his hands, especially, if he's tinkering with something. Never one for highly theoretical subjects in school, one of his favourite hobbies is to take apart small electronics and put them back together to figure out how they work. With the aim of winning \$10 for a local children's charity, which of the following do you think is most likely to be true?

a.) Michael is a germaphobe and is a mechanic.

b.) Michael is a germaphobe and is not a mechanic.

c.) Michael is a mechanic and not a germaphobe.

d.) Michael is neither a germaphobe nor a mechanic. 


\section{Appendix C: Experimental Stimuli for Chapter 5}

\section{Experiment 1}

\section{Instructions}

You will be presented with a series of descriptions of various people. You will then be asked to judge, given the description of the person, which of a set of new descriptions is most likely to be true about the person. You will not have enough information to know for sure, but your goal is to be right so you should pick the one that strikes you as most likely to be right. To encourage this, we ask you to imagine that for each correct choice you make $\$ 10$ will go to a local children's charity, and that no money is associated with incorrect choices.

1. John is a powerful banker. He makes lots of money, he drives a Benz (when he's not being driven around in limousines), he travels a lot, and he has a penthouse suite in a fancy condo. With the aim of winning $\$ 10$ for a local children's charity, which of the following do you think is most likely to be true?
a.) John lives in New York.
b.) John lives in the United States.
c.) John lives in Poland.
d.) John lives in Vancouver.

2. Olivia was a heavy smoker. It was a rare occurrence to see her without a cigarette in hand. She would often buy packs of Viceroy cigarettes in bulk. Olivia sadly died earlier in the year. With the aim of winning $\$ 10$ for a local children's charity, which of the following do you think is most likely to be true?
a.) Olivia died from lung cancer.
b.) Olivia died from some disease or other.
c.) Olivia died from a plane crash.
d.) Olivia died from a natural disaster.

3. Reggie loves watching basketball. He analyzes strategies and the plays of his favourite team like it's his 
job. He idolizes Kawhi Leonard, Lebron James and Michael Jordan, and you can find their signed jerseys on prominent display in his room. With the aim of winning $\$ 10$ for a local children's charity, which of the following do you think is most likely to be true?
a.) Reggie plays basketball.
b.) Reggie plays at least one sport.
c.) Reggie is a fan of classical jazz.
d.) Reggie is a fan of graphic novels.

4. Anna is travelling abroad for the summer. Where she's headed, she's planning on eating copious amounts of pasta, gelato and visiting fresco paintings. She's preparing to learn a Romance language. With the aim of winning $\$ 10$ for a local children's charity, which of the following do you think is most likely to be true?
a.) Anna is going to Italy.
b.) Anna is going to Europe.
c.) Anna is going to Argentina.
d.) Anna is going to Johannesburg.

5. Anthony loves greasy foods and hates exercising. He has a genetic history of cardiac disease on both his paternal and maternal side. His physician tells him that he will need to take steps to manage the damage caused from this lifestyle very soon in the future. With the aim of winning $\$ 10$ for a local children's charity, which of the following do you think is most likely to be true?
a.) Anthony will need a heart transplant.
b.) Anthony will need surgery.
c.) Anthony will need a subscription to the Financial Times newspaper.
d.) Anthony will need a pet.

6. Kim lives in a senior's complex with 100 units. Most people have pets: 90 of the units have dogs, 5 of them have cats. Only 5 have no pets in them at all. With the aim of winning $\$ 10$ for a local children's charity, which of the following do you think is most likely to be true? 

a.) Kim has a dog.
b.) Kim has a pet.
c.) Kim enjoys playing hockey.
d.) Kim likes coffee.

7. Eric wants to pick something up the farmer's market. At this market, most of the items are locally grown produce: around 80 percent of the vendors sell fruits and around 15 percent sell vegetables. Around 5 percent sell handmade housewares. With the aim of winning $\$ 10$ for a local children's charity, which of the following do you think is most likely to be true?
a.) Eric bought fruit.
b.) Eric bought produce.
c.) Eric likes to roller-skate.
d.) Eric is a puppeteer.

8. Taylor has always been a very happy person who enjoys life to the maximum. When Sandy was in college, they almost always had more than one girlfriend. Sandy likes diversity in life and therefore was never satisfied by a steady companion. Sandy is now 35 years old.With the aim of winning $\$ 10$ for a local children's charity, which of the following do you think is most likely to be true?
a.) Taylor is a bachelor.
b.) Taylor is a man.
c.) Taylor works for NASA.
d.) Taylor is allergic to onions.

9. Jasmine is from a place that is known for its rich ancient history and civilizations. This place is also known for its sand structures and abundant deserts. It is also features the Nile River. With the aim of winning $\$ 10$ for a local children's charity, which of the following do you think is most likely to be true?
a.) Jasmine is from Egypt.
b.) Jasmine is from Africa. 
c.) Jasmine is from Paraguay.

d.) Jasmine is from Antarctica.

10. Sandy is very laid back. She dresses for sunny, warm weather that persists practically year-round. She lives close to the beach, in an area that is very nutritionally and environmentally conscientious. With the aim of winning $\$ 10$ for a local children's charity, which of the following do you think is most likely to be true?

a.) Sandy lives in California.

b.) Sandy lives in America.

c.) Sandy lives in Rotterdam.

d.) Sandy lives in the Central African Republic.

\section{Experiment 2}

\section{Instructions}

You will be presented with a series of descriptions of various people. You will then be asked to judge, given the description of the person, which of a set of new descriptions is most likely to be true about the person. You will not have enough information to know for sure, but your goal is to be right so you should pick the one that strikes you as most likely to be right. To encourage this, we ask you to imagine that for each correct choice you make $\$ 10$ will go to a local children's charity, and that no money is associated with incorrect choices.

1. John is a powerful banker. He makes lots of money, he drives a Benz (when he's not being driven around in limousines), he travels a lot, and he has a penthouse suite in a fancy condo. With the aim of winning \$10 for a local children's charity, which of the following do you think is most likely to be true?

a.) John lives in New York or the United States.

b.) John lives in Papua New Guinea or the United States.

c.) John lives in Poland.

d.) John lives in Vancouver. 
2. Olivia was a heavy smoker. It was a rare occurrence to see her without a cigarette in hand. She would often buy packs of Viceroy cigarettes in bulk. Olivia sadly died earlier in the year. With the aim of winning $\$ 10$ for a local children's charity, which of the following do you think is most likely to be true?

a.) Olivia died from lung cancer or some disease.

b.) Olivia died from falling downstairs or some disease.

c.) Olivia died from a plane crash.

d.) Olivia died from a natural disaster.

3. Reggie loves watching basketball. He analyzes strategies and the plays of his favourite team like it's his job. He idolizes Kawhi Leonard, Lebron James and Michael Jordan, and you can find their signed jerseys on prominent display in his room. With the aim of winning $\$ 10$ for a local children's charity, which of the following do you think is most likely to be true?

a.) Reggie plays basketball.

b.) Reggie plays at least one sport.

c.) Reggie is a fan of classical jazz.

d.) Reggie is a fan of graphic novels.

4. Anna is travelling abroad for the summer. Where she's headed, she's planning on eating copious amounts of pasta, gelato and visiting fresco paintings. She's preparing to learn a Romance language. With the aim of winning $\$ 10$ for a local children's charity, which of the following do you think is most likely to be true?
a.) Anna is going to Italy or Europe.
b.) Anna is going to North America or Europe.
c.) Anna is going to Argentina.
d.) Anna is going to Johannesburg.

5. Anthony loves greasy foods and hates exercising. He has a genetic history of cardiac disease on both his paternal and maternal side. His physician tells him that he will need to take steps to manage the damage 
caused from this lifestyle very soon in the future. With the aim of winning $\$ 10$ for a local children's charity, which of the following do you think is most likely to be true?

a.) Anthony will need a heart transplant.

b.) Anthony will need surgery.

c.) Anthony will need a subscription to the Financial Times newspaper.

d.) Anthony will need a pet.

6. Kim lives in a senior's complex with 100 units. Most people have pets: 90 of the units have dogs, 5 of them have cats. Only 5 have no pets in them at all. With the aim of winning $\$ 10$ for a local children's charity, which of the following do you think is most likely to be true?

a.) Kim has a dog or a pet.

b.) Kim has a daughter or a pet.

c.) Kim enjoys playing hockey.

d.) Kim likes coffee.

7. Eric wants to pick something up the farmer's market. At this market, most of the items are locally grown produce: around 80 percent of the vendors sell fruits and around 15 percent sell vegetables. Around 5 percent sell handmade housewares. With the aim of winning \$10 for a local children's charity, which of the following do you think is most likely to be true?

a.) Eric bought fruit or produce.

b.) Eric bought wood or produce.

c.) Eric likes to roller-skate.

d.) Eric is a puppeteer.

8. Taylor has always been a very happy person who enjoys life to the maximum. When Sandy was in college, they almost always had more than one girlfriend. Sandy likes diversity in life and therefore was never satisfied by a steady companion. Sandy is now 35 years old.With the aim of winning $\$ 10$ for a local children's charity, which of the following do you think is most likely to be true? 

a.) Taylor is a bachelor or a man.
b.) Taylor is a nurse or a man.
c.) Taylor works for NASA.
d.) Taylor is allergic to onions.

9. Jasmine is from a place that is known for its rich ancient history and civilizations. This place is also known for its sand structures and abundant deserts. It is also features the Nile River. With the aim of winning $\$ 10$ for a local children's charity, which of the following do you think is most likely to be true?
a.) Jasmine is from Egypt or Africa.
b.) Jasmine is from Asia or Africa.
c.) Jasmine is from Paraguay.
d.) Jasmine is from Antarctica.

10. Sandy is very laid back. She dresses for sunny, warm weather that persists practically year-round. She lives close to the beach, in an area that is very nutritionally and environmentally conscientious. With the aim of winning $\$ 10$ for a local children's charity, which of the following do you think is most likely to be true?
a.) Sandy lives in California or America.
b.) Sandy lives in Norway or America.
c.) Sandy lives in Rotterdam.
d.) Sandy lives in the Central African Republic. 


\section{Bibliography}

Adler, J. E. (1984). Abstraction is uncooperative. Journal for the Theory of Social Behaviour, 14(2):165-181.

Agnoli, F. and Krantz, D. H. (1989). Suppressing natural heuristics by formal instruction: The case of the conjunction fallacy. Cognitive Psychology, 21(4):515-550.

Aloni, M. (2005). A formal treatment of the pragmatics of questions and attitudes. Linguistics and Philosophy, 28(5):505-539.

Alonso-Ovalle, L. (2006). Disjunction in Alternative Semantics. PhD thesis, University of Massachusetst, Amherst.

Asher, N. and Lascarides, A. (2013). Strategic conversation. Semantics and Pragmatics, 6:2-1.

Atlas, J. D. and Levinson, S. C. (1981). It-clefts, informativeness and logical form: Radical pragmatics (revised standard version. In Radical Pragmatics, pages 1-62. Academic Press.

Baayen, R. H., Davidson, D. J., and Bates, D. M. (2008). Mixed-effects modeling with crossed random effects for subjects and items. Journal of memory and language, 59(4):390-412.

Bach, K. (2006). The Top Ten Misconceptions about Implicature. Drawing the boundaries of meaning: Neo-Gricean studies in pragmatics and semantics in honor of Laurence R. Horn, pages 21-30.

Bar-Hillel, M. and Neter, E. (1993). How alike is it versus how likely is it: A disjunction fallacy in probability judgments. Journal of Personality and Social Psychology, 65(6):1119.

Barr, D. J., Levy, R., Scheepers, C., and Tily, H. J. (2013). Random effects structure for confirmatory hypothesis testing: Keep it maximal. Journal of memory and language, 68(3):255-278. 
Bates, D., Mächler, M., Bolker, B., and Walker, S. (2015). Fitting linear mixed-effects models using lme4. Journal of Statistical Software, 67(1):1-48.

Beck, S. and Rullmann, H. (1999). A flexible approach to exhaustivity in questions. Natural Language Semantics, 7(3):249-298.

Belnap, N. D. and Steel, T. B. (1976). The logic of questions and answers. New Haven : Yale University Press.

Bergen, L., Levy, R., and Goodman, N. (2016). Pragmatic reasoning through semantic inference. Semantics and Pragmatics, 9.

Bott, L. and Noveck, I. A. (2004). Some utterances are underinformative: The onset and time course of scalar inferences. Journal of memory and language, 51(3):437-457.

Braine, M. D. and Rumain, B. (1981). Development of comprehension of “or": Evidence for a sequence of competencies. Journal of experimental child psychology, 31(1):46-70.

Breheny, R. (2008). A new look at the semantics and pragmatics of numerically quantified noun phrases. Journal of Semantics, 25(2):93-139.

Breheny, R., Katsos, N., and Williams, J. (2006). Are generalised scalar implicatures generated by default? an on-line investigation into the role of context in generating pragmatic inferences. Cognition, 100(3):434463.

Breheny, R., Klinedinst, N., Romoli, J., and Sudo, Y. (2018). The Symmetry Problem: Current Theories and Prospects. Natural Language Semantics, 26(2):85-110.

Capone, A. (2009). Are Explicatures Cancellable? Toward a Theory of the Speaker's Intentionality. Intercultural Pragmatics, 6(1):55-83.

Capone, A. (2010). What can Modularity of Mind Tell us About the Semantics/Pragmatics Debate? Australian Journal of linguistics, 30(4):497-520.

Carlson, B. W. and Yates, J. F. (1989). Disjunction errors in qualitative likelihood judgment. Organizational Behavior and Human Decision Processes, 44(3):368-379. 
Carston, R. (2004). Relevance theory and the saying/implicating distinction. En LR Horn \& G. Ward (Eds.), The handbook of pragmatics (pp. 633-656).

Chemla, E. and Singh, R. (2014a). Remarks on the experimental turn in the study of scalar implicature, part i. Language and Linguistics Compass, 8(9):373-386.

Chemla, E. and Singh, R. (2014b). Remarks on the experimental turn in the study of scalar implicature, part ii. Language and Linguistics Compass, 8(9):387-399.

Chemla, E. and Spector, B. (2011). Experimental evidence for embedded scalar implicatures. Journal of semantics, 28(3):359-400.

Chierchia, G. et al. (2004). Scalar implicatures, polarity phenomena, and the syntax/pragmatics interface. Structures and beyond, 3:39-103.

Chierchia, G., Fox, D., and Spector, B. (2008). The grammatical view of scalar implicatures and the relationship between semantics and pragmatics.

Chierchia, G., Fox, D., and Spector, B. (2012). The Grammatical View of Scalar Implicatures and the Relationship between Semantics and Pragmatics, volume 3, pages 2297-2332. de Gruyter.

Ciardelli, I. and Roelofsen, F. (2017). Hurford's constraint, the semantics of disjunction, and the nature of alternatives. Natural Language Semantics, 25(3):199-222.

Clifton Jr, C. and Dube, C. (2010). Embedded implicatures observed: a comment on. Semantics and pragmatics, 3(7):1.

Collins, A. M. and Quillian, M. R. (1969). Retrieval time from semantic memory. Journal of verbal learning and verbal behavior, 8(2):240-247.

De Neys, W. and Schaeken, W. (2007). When people are more logical under cognitive load: Dual task impact on scalar implicature. Experimental psychology, 54(2):128-133.

Degen, J. and Tanenhaus, M. K. (2015). Processing scalar implicature: A constraint-based approach. Cognitive science, 39(4):667-710. 
Dekker, P., Aloni, M., and Butler, A. (2007). 1: The semantics and pragmatics of questions. In Questions in dynamic semantics, pages 1-40. Brill.

Dieuleveut, A., Chemla, E., and Spector, B. (2019). Distinctions between primary and secondary scalar implicatures. Journal of Memory and Language, 106:150-171.

Dulany, D. E. and Hilton, D. J. (1991). Conversational implicature, conscious representation, and the conjunction fallacy. Social Cognition, 9(1):85-110.

Dulcinati, G. and Pouscoulous, N. (2016). Cooperation and exhaustification. Pre-proceedings of Trends in Experimental Pragmatics, pages 39-45.

Evans, J. S. B. and Newstead, S. (1980). A study of disjunctive reasoning. Psychological research, 41(4):373388.

Feeney, A., Scrafton, S., Duckworth, A., and Handley, S. J. (2004). The story of some: Everyday pragmatic inference by children and adults. Canadian Journal of Experimental Psychology/Revue canadienne de psychologie expérimentale, 58(2):121.

Fiedler, K. (1988). The dependence of the conjunction fallacy on subtle linguistic factors. Psychological research, 50(2):123-129.

Fillenbaum, S. (1974). Or: Some uses. Journal of Experimental Psychology, 103(5):913.

Fox, D. (2007). Free choice and the theory of scalar implicatures. In Presupposition and implicature in compositional semantics, pages 71-120. Springer.

Fox, D. (2014). Cancelling the Maxim of Quantity: Another challenge for a Gricean theory of Scalar Implicatures. Semantics and Pragmatics, 7:1-20.

Fox, D. and Katzir, R. (2011). On the characterization of alternatives. Natural language semantics, 19(1):87107.

Gazdar, G. (1979). Pragmatics: implicature, presupposition and logical form. Indiana University Linguistics Club.

Geurts, B. (2006). The meaning and use of a number word. Non-definiteness and plurality, 95:311. 
Geurts, B. (2009). Scalar implicature and local pragmatics. Mind \& Language, 24(1):51-79.

Geurts, B. (2010). Quantity implicatures. Cambridge University Press.

Geurts, B. and Pouscoulous, N. (2009). Embedded implicatures?!? Semantics and pragmatics, 2:4-1.

Gigerenzer, G. (1994). Why the distinction between single-event probabilities and frequencies is important for psychology (and vice versa). In Subjective probability, pages 129-161. Wiley.

Goodman, N. D. and Stuhlmüller, A. (2013). Knowledge and implicature: Modeling language understanding as social cognition. Topics in cognitive science, 5(1):173-184.

Grice, H. P. (1975). Logic and Conversation. In Cole, P. and Morgan, J. L., editors, Syntax and Semantics: Vol. 3: Speech Acts, pages 41-58. Academic Press, New York.

Grice, H. P. (1989). Studies in the Way of Words. Harvard University Press.

Grodner, D. J., Klein, N. M., Carbary, K. M., and Tanenhaus, M. K. (2010). “some,” and possibly all, scalar inferences are not delayed: Evidence for immediate pragmatic enrichment. Cognition, 116(1):42-55.

Groenendijk, J. and Stokhof, M. Partitioning logical space.

Groenendijk, J. A. G. and Stokhof, M. J. B. (1984). Studies on the Semantics of Questions and the Pragmatics of Answers. PhD thesis, Univ. Amsterdam.

Gualmini, A., Hulsey, S., Hacquard, V., and Fox, D. (2008). The question-answer requirement for scope assignment. Natural language semantics, 16(3):205.

Hamblin, C. L. (1958). Questions. The Australasian Journal of Philosophy, 36:159-68.

Harnish, R. M. et al. (1976). Logical form and implicature. An integrated theory of linguistic ability, $313: 391$.

Haugh, M. (2013). Implicature, inference and cancellability. In Perspectives on Pragmatics and Philosophy, pages 133-151. Springer.

Hertwig, R., Benz, B., and Krauss, S. (2008). The conjunction fallacy and the many meanings of and. Cognition, 108(3):740-753. 
Hertwig, R. and Gigerenzer, G. (1999). The ‘conjunction fallacy'revisited: How intelligent inferences look like reasoning errors. Journal of behavioral decision making, 12(4):275-305.

Hirschberg, J. B. (1985). A theory of scalar implicature (natural languages, pragmatics, inference). $\mathrm{PhD}$ thesis, University of Pennsylvania.

Hirschberg, J. L. B. (1991). A Theory of Scalar Implicature. New York: Garland Pub.

Horn, L. R. (1972). On The Semantic Properties Of Logical Operators In English. PhD thesis, University of California, Los Angeles, CA.

Horn, L. R. (1985). Metalinguistic negation and pragmatic ambiguity. Language, 61(1):121-174.

Horn, L. R. and Ward, G. L. (2004). The Handbook of Pragmatics. Wiley Online Library.

Huitink, J. and Spenader, J. (2004). Cancelation Resistant PCIs. In Proceedings of the ESSLLI 2004 workshop on implicature and conversational meaning, pages 8-13.

Hurford, J. R. (1974). Exclusive or inclusive disjunction. Foundations of language, 11(3):409-411.

Kahneman, D. (2003). A perspective on judgment and choice: Mapping bounded rationality. American psychologist, pages 697-720.

Kahneman, D., Slovic, S. P., Slovic, P., and Tversky, A. (1982). Judgment under uncertainty: Heuristics and biases. Cambridge university press.

Katzir, R. (2007). Structurally-defined alternatives. Linguistics and Philosophy, 30(6):669-690.

Katzir, R. and Singh, R. (2014). Hurford disjunctions: embedded exhaustification and structural economy. In Proceedings of sinn und bedeutung, volume 18, pages 201-216.

Kearns, K. (2011). Semantics. New York: Palgrave Macmillan.

Ladusaw, W. (1980). Polarity sensitivity as inherent scope relations. Outstanding dissertations in linguistics. Garland Pub.

Lakoff, G. (1987). Women, fire, and dangerous things. University of Chicago press. 
Larson, M., Doran, R., McNabb, Y., Baker, R., Berends, M., Djalali, A., and Ward”, G. ("2009”). ”Distinguishing the SAID from the IMPLICATED Using a Novel Experimental Paradigm", pages "74-93". "Palgrave Macmillan".

Levinson, S. C. (1983). Pragmatics. Cambridge Textbooks in Linguistics. Cambridge University Press.

Levinson, S. C. (2000). Presumptive meanings: The theory of generalized conversational implicature. MIT press.

Lewis, D. (1969). Convention: a philosophical study. Cambridge: Harvard University Press.

Maguire, P., Moser, P., Maguire, R., and Keane, M. T. (2018). Why the conjunction effect is rarely a fallacy: How learning influences uncertainty and the conjunction rule. Frontiers in psychology, 9:1011.

Marty, P., Chemla, E., and Spector, B. (2013). Interpreting numerals and scalar items under memory load. Lingua, 133:152-163.

Matsumoto, Y. (1995). The conversational condition on Horn scales. Linguistics and philosophy, 18(1):2160.

Mellers, B., Hertwig, R., and Kahneman, D. (2001). Do frequency representations eliminate conjunction effects? an exercise in adversarial collaboration. Psychological Science, 12(4):269-275.

Meyer, M.-C. (2014). Deriving hurford's constraint. In Semantics and linguistic theory, volume 24, pages $577-596$.

Meyer, M.-C. (2018). An apple or a pear: free choice disjunction. Wiley's semantics companion.

Meyer, M.-C. et al. (2013). Ignorance and grammar. PhD thesis, Massachusetts Institute of Technology.

Moro, R. (2009). On the nature of the conjunction fallacy. Synthese, 171(1):1-24.

Mosconi, G. and Macchi, L. (2001). The role of pragmatic rules in the conjunction fallacy. Mind \& Society, 2(1):31-57.

Nickel, B. (2010). Generically free choice. Linguistics and Philosophy, 33(6):479-512. 
Nisbett, R. E., Krantz, D. H., Jepson, C., and Kunda, Z. (1983). The use of statistical heuristics in everyday inductive reasoning. Psychological review, 90(4):339.

Noveck, I. A. (2001). When children are more logical than adults: Experimental investigations of scalar implicature. Cognition, 78(2):165-188.

Noveck, I. A., Chierchia, G., Chevaux, F., Guelminger, R., and Sylvestre, E. (2002). Linguistic-pragmatic factors in interpreting disjunctions. Thinking \& Reasoning, 8(4):297-326.

Pagin, A. (2019). Exploring the conjunction fallacy in probability judgment: Conversational implicature or nested sets? Journal of European Psychology Students, 10(2).

Papafragou, A. and Musolino, J. (2003). Scalar implicatures: experiments at the semantics-pragmatics interface. Cognition, 86(3):253-282.

Partee, B. and Rooth, M. (1983). Generalized conjunction and type ambiguity. Formal semantics: the essential readings, pages 334-356.

Politzer, G. and Noveck, I. A. (1991). Are conjunction rule violations the result of conversational rule violations? Journal of psycholinguistic research, 20(2):83-103.

Potts, C. (2015). Presupposition and implicature. In Lappin, S. and Fox, C., editors, The Handbook of Contemporary Semantic Theory, pages 168-202. Wiley-Blackwell, 2 edition.

Potts, C. and Levy, R. (2015). Negotiating lexical uncertainty and speaker expertise with disjunction. In Proceedings of the Annual Meeting of the Berkeley Linguistics Society, volume 41.

Pryslopska, A. (2013). Implicature in uncooperative contexts. Master's thesis, University of Tubingen.

R Core Team (2019). R: A Language and Environment for Statistical Computing. R Foundation for Statistical Computing, Vienna, Austria.

Roberts, C. (1996). Information structure: Towards an integrated theory of formal pragmatics, volume 49 of. Technical report, OSU Working Papers in Linguistics.

Roelofsen, F. (2019). Semantic theories of questions. In Oxford Research Encyclopedia of Linguistics. 
Rosch, E. (1975). Cognitive representations of semantic categories. Journal of experimental psychology: General, 104(3):192.

Rosch, E., Mervis, C. B., Gray, W. D., Johnson, D. M., and Boyes-Braem, P. (1976). Basic objects in natural categories. Cognitive Psychology, 8(3):382-439.

Rosch, E. H. (1973). Natural categories. Cognitive Psychology, 4(3):328-350.

Sauerland, U. (2004). Scalar implicatures in complex sentences. Linguistics and philosophy, 27(3):367-391.

Sauerland, U. (2005). The epistemic step. Experimental Pragmatics, 10.

Sauerland, U. (2017). Disjunction and implicatures: Some notes on recent developments. In Contrastiveness in Information Structure, Alternatives and Scalar Implicatures, pages 245-259. Springer.

Schulz, K. and Van Rooij, R. (2006). Pragmatic meaning and non-monotonic reasoning: The case of exhaustive interpretation. Linguistics and philosophy, 29(2):205-250.

Simons, M. (2001). Disjunction and alternativeness. Linguistics and Philosophy, pages 597-619.

Singh, R. (2008). On the interpretation of disjunction: Asymmetric, incremental, and eager for inconsistency. Linguistics and Philosophy, 31(2):245-260.

Singh, R. (2019). Context, content, and the occasional costs of implicature computation. Frontiers in Psychology, 10:2214.

Singh, R., Wexler, K., Astle-Rahim, A., Kamawar, D., and Fox, D. (2016). Children interpret disjunction as conjunction: Consequences for theories of implicature and child development. Natural Language Semantics, 24(4):305-352.

Spector, B. (2013). Bare numerals and scalar implicatures. Language and Linguistics Compass, 7(5):273294.

Sperber, D. and Wilson, D. (1986). Relevance: Communication and cognition, volume 142. Harvard University Press Cambridge, MA.

Stanovich, K. E. and West, R. F. (2000). Individual differences in reasoning: Implications for the rationality debate? Behavioral and brain sciences, 23(5):645-665. 
Stolarz-Fantino, S., Fantino, E., Zizzo, D. J., and Wen, J. (2003). The conjunction effect: New evidence for robustness. The American Journal of Psychology.

Tentori, K., Bonini, N., and Osherson, D. (2004). The conjunction fallacy: a misunderstanding about conjunction? Cognitive Science, 28(3):467-477.

Tentori, K., Crupi, V., and Russo, S. (2013). On the determinants of the conjunction fallacy: Probability versus inductive confirmation. Journal of Experimental Psychology: General, 142(1):235.

Tieu, L., Romoli, J., Zhou, P., and Crain, S. (2015). Children's knowledge of free choice inferences and scalar implicatures. Journal of Semantics, 33(2):269-298.

Tversky, A. and Kahneman, D. (1974). Judgment under uncertainty: Heuristics and biases. science, 185(4157):1124-1131.

Tversky, A. and Kahneman, D. (1983). Extensional versus intuitive reasoning: The conjunction fallacy in probability judgment. Psychological review, 90(4):293-315.

Van Benthem, J. (1987). Meaning: interpretation and inference. Synthese, pages 451-470.

Van Rooij, R. and Schulz, K. (2004). Exhaustive interpretation of complex sentences. Journal of logic, language and information, 13(4):491-519.

van Rooy, R. (2003a). Conversational implicatures and communication theory. In Current and new directions in discourse and dialogue, pages 283-303. Springer.

van Rooy, R. (2003b). Questioning to resolve decision problems. Linguistics and Philosophy, 26(6):727-763.

van Rooy, R. (2004). Utility of mention-some questions. Research on Language and Computation, 2(3):401416.

von Fintel, K. and Heim, I. (1985). 24.954: Pragmatics in linguistic theory.

Wedell, D. H. and Moro, R. (2008). Testing boundary conditions for the conjunction fallacy: Effects of response mode, conceptual focus, and problem type. Cognition, 107(1):105-136.

Weiner, M. (2006). Are All Conversational Implicatures Cancellable? Analysis, 66(2):127-130. 
Wells, G. L. (1985). The conjunction error and the representativeness heuristic. Social Cognition, 3(3):266279.

Westera, M. (2018a). An attention-based explanation for some exhaustivity operators. In Proceedings of Sinn und Bedeutung, volume 21, pages 1307-1324.

Westera, M. (2018b). A pragmatic approach to hurford disjunctions. Under Review.

Westera, M. (2020). Hurford disjunctions: an in-depth comparison of the grammatical and the pragmatic approach. Under review.

Zakkou, J. (2018). The cancellability test for conversational implicatures. Philosophy Compass, 13(12):e12552.

Zipf, G. K. (1949). Human Behavior and the Principle of Least Effort. addison-wesley press.

Zondervan, A., Meroni, L., and Gualmini, A. (2008). Experiments on the role of the question under discussion for ambiguity resolution and implicature computation in adults. In Semantics and linguistic theory, volume 18, pages $765-777$. 